\title{
ATIVIDADE CONVECTIVA ASSOCIADA ÀS ANOMALIAS DE TEMPERATURA DA SUPERFÍCIE DO MAR NO ATLÂNTICO TROPICAL E IMPACTOS CLIMÁTICOS NO ESTADO DE MINAS GERAIS
}

\author{
CARPENEDO, Camila Bertoletti - camila.carpenedo@ufu.br \\ Universidade Federal de Uberlândia / UFU
}

\begin{abstract}
RESUMO: Em Minas Gerais (MG), o ciclo anual da precipitação apresenta características marcadas por uma estação seca e outra úmida. Essa sazonalidade é típica de um Sistema de Monção, o qual é influenciado pela variabilidade da temperatura da superfície do mar (TSM) do oceano Atlântico. O objetivo deste estudo foi investigar a atividade convectiva associada às anomalias de TSM no Atlântico tropical, através dos índices climáticos Tropical Southern Atlantic (TSA) e Tropical Northern Atlantic (TNA), bem como o padrão espacial sazonal de precipitação e temperatura do ar sobre o Brasil, com foco em MG. Os resultados mostram que eventos frios (quentes) do TSA e eventos quentes (frios) do TNA estão associados com um deslocamento anômalo para norte (para sul) da Zona de Convergência Intertropical do Atlântico. Eventos frios (quentes) do TSA (TNA) estão associados com um padrão espacial de anomalias de precipitação sobre o Brasil semelhante ao padrão de gangorra associado à Zona de Convergência do Atlântico Sul, indicando uma maior (menor) atividade convectiva. Desta forma, em MG há anomalias positivas (negativas) de precipitação e anomalias negativas (positivas) de temperatura do ar na primavera e verão. Este estudo evidencia a importância de monitorar as anomalias de TSM no Atlântico tropical para melhor compreender e prever as variações de precipitação e temperatura do ar no estado de MG.
\end{abstract}

PALAVRAS-CHAVE: Oceano Atlântico tropical, atividade convectiva, precipitação, Estado de Minas Gerais

CONVECTIVE ACTIVITY ASSOCIATED WITH THE TROPICAL ATLANTIC SEA SURFACE TEMPERATURE ANOMALIES AND CLIMATE IMPACTS IN THE STATE OF MINAS GERAIS

\begin{abstract}
In the southern-central Brazilian state of Minas Gerais (MG), the annual precipitation cycle presents marked characteristics of a dry and wet season. This seasonality is typical of the Monsoon System, which is influenced by the variability of the sea surface temperature (SST) in the Atlantic Ocean. Thus, the objective of this study was to investigate the convective activity associated with SST anomalies in the tropical Atlantic through the Tropical Southern Atlantic (TSA) and Tropical Northern Atlantic (TNA) climate indices, as well as the seasonal spatial pattern of precipitation and air temperature over Brazil, focusing on MG. The results show that TSA cold (hot) events and hot (cold) TNA events are associated with an anomalous shift north (south) of the Atlantic Intertropical Convergence Zone. TSA (TNA) cold (hot) events are associated with a spatial pattern of precipitation anomalies over Brazil similar to the seesaw pattern associated with the South Atlantic Convergence Zone, indicating a higher (lower) convective activity. Thus, in MG there are positive (negative) precipitation anomalies and negative (positive) air temperature anomalies in spring and summer. This study highlights the importance of monitoring SST anomalies in the tropical Atlantic to better understand and predict variations in precipitation and air temperature in the state of MG.
\end{abstract}

KEYWORDS: Tropical Atlantic Ocean, convective activity, precipitation, state of Minas Gerais

ACTIVIDAD CONVECTIVA ASOCIADA A LAS ANOMALIAS DE TEMPERATURA DE LA SUPERFICIE DEL MAR EN EL ATLÁNTICO TROPICAL E IMPACTOS CLIMÁTICOS EN EL ESTADO DE MINAS GERAIS

RESUMEN: En Minas Gerais (MG), el ciclo anual de la precipitación presenta características marcadas por una estación seca y otra húmeda. Esta estacionalidad es típica de un Sistema de Monción, el cual es influenciado por la variabilidad de la temperatura de la superficie del mar (TSM) del océano Atlántico. El objetivo de este 
estudio fue investigar la actividad convectiva asociada a las anomalías de TSM en el Atlántico tropical, a través de los índices climáticos Tropical Southern Atlantic (TSA) y Tropical Northern Atlantic (TNA), así como el patrón espacial estacional de precipitación y temperatura del aire sobre el "Brasil, con foco en MG. Los resultados muestran que los eventos fríos (cálidos) del TSA y los eventos calientes (fríos) del TNA se asocian con un desplazamiento anómalo hacia el norte (hacia el sur) de la Zona de Convergencia Intertropical del Atlántico. Los eventos fríos (cálidos) del TSA (TNA) están asociados con un patrón espacial de anomalías de precipitación sobre Brasil, similar al patrón de gangorra asociado a la Zona de Convergencia del Atlántico Sur, indicando una mayor (menor) actividad convectiva. De esta forma, en MG hay anomalías positivas (negativas) de precipitación y anomalías negativas (positivas) de temperatura del aire en la primavera y verano. Este estudio evidencia la importancia de monitorear las anomalías de TSM en el Atlántico tropical para comprender mejor y predecir las variaciones de precipitación y temperatura del aire en el estado de MG

PALABRAS CLAVE: Océano Atlántico tropical, actividad convectiva, precipitación, Estado de Minas Gerais

\section{INTRODUÇÃO}

Embora $70 \%$ da superfície terrestre sejam cobertas por água, com um volume total de $1,4 \times 10^{9} \mathrm{~km}^{3}$, apenas $0,007 \%$ deste volume são aproveitáveis pelos seres humanos (CHRISTOPHERSON, 2012). Minas Gerais (MG) possui uma população estimada de 21,1 milhões de habitantes, o que corresponde a $10,1 \%$ da população brasileira, sendo o segundo estado mais populoso do país (IBGE, 2018). MG é abarcado por quatro Regiões Hidrográficas, as quais comportam $10 \%$ do total de água doce superficial do Brasil, sendo 2,1\% no São Francisco (noroeste de MG), 0,3\% no Atlântico Leste (nordeste de MG), 1,2\% no Atlântico Sudeste (sudeste de MG) e 6,4\% no Paraná (sudoeste de MG) (ANA, 2010). Desta forma, fica evidente que a hidrosfera aproveitável é suficiente, mas irregularmente distribuída no Estado.

A disponibilidade de água potável na Terra, tanto em quantidade como qualidade, diminui gradualmente devido ao crescimento populacional, à expansão das fronteiras agrícolas e à degradação do meio ambiente. Entre 2000 e 2017 a população mineira cresceu cerca de 16\% (IBGE, 2010). Com o aumento populacional e, consequentemente, com o crescimento das ocupações urbanas sobre os mananciais de abastecimento público, os problemas associados à poluição hídrica se agravou principalmente nos grandes centros urbanos (ANA, 2010), os quais comportam $85 \%$ da população de MG (IBGE, 2010). Somado a isso, existe um aumento de demanda por água principalmente para geração de energia elétrica e produção de alimentos. Em MG a irrigação responde pela maior parcela de água consumida (ANA, 2017). Entre 2006 e 2015 mais do que dobrou a área irrigada no Estado, que passou de 524.682 $\mathrm{km}^{2}$ para $1.082 .373 \mathrm{~km}^{2}$ (ANA, 2017).

O ciclo anual da precipitação na América do Sul tropical, o que inclui o Estado de MG, apresenta características marcadas por uma estação seca e outra úmida (SILVA; KOUSKY, 2012; SILVA; REBOITA, 2013; REBOITA et al., 2015). Mais de $50 \%$ do total anual da precipitação ocorre durante o verão e menos de 5\% durante o inverno (SILVA; KOUSKY, 2012). Desta forma, a precipitação é irregularmente distribuída ao longo do ano. Estas características de inverno seco e verão chuvoso são típicos de um Sistema de Monção (RAO; CAVALCANTI; HADA, 1996; KOUSKY; ROPELEWSKI, 1997; GRIMM, 2003; GAN; KOUSKY; ROPELEWSKI, 2004). 
O Sistema de Monção da América do Sul tipicamente inicia durante a primavera, com aumento da convecção sobre o noroeste da Bacia Amazônica em meados de setembro e avança para o sudeste do Brasil em meados de novembro (VERA et al., 2006; SILVA; KOUSKY, 2012). No final de novembro há convecção profunda sobre grande parte da América do Sul central, do equador até $20^{\circ} \mathrm{S}$. Ao longo desse período, convecção profunda associada à Zona de Convergência Intertropical (ZCIT) do Atlântico está confinada no Atlântico Norte central, entre 5-8 $\mathrm{N}$ (ZHOU; LAU, 1998; VERA et al., 2006). Na fase madura, entre final de novembro e final de fevereiro, a atividade convectiva principal está localizada sobre o Brasil central e associada com uma banda de nebulosidade e precipitação que se estende do sul da Amazônia ao sudeste do Brasil e Atlântico Sul adjacente, denominada de Zona de Convergência do Atlântico Sul (ZCAS) (VERA et al., 2006). No final do verão começa a fase de decaimento da estação chuvosa, quando há o deslocamento da convecção para o equador.

Estudos mostram que o ciclo de vida do Sistema de Monção da América do Sul é influenciado pela variabilidade da temperatura da superfície do mar (TSM) nos oceanos Atlântico e Pacífico. A ocorrência de eventos de El NiñoOscilação Sul (ENOS) induz a anomalias de TSM no Atlântico tropical, levando à configuração de um dipolo de anomalias entre o Atlântico tropical Norte e Sul (e.g., GIANNINI, KUSHNIR; CANE, 2000; RODRIGUES et al., 2011), conhecido como Dipolo do Atlântico (MOURA; SHUKLA, 1981), que é um dos fatores responsáveis pelo deslocamento meridional da ZCIT do Atlântico (CHIANG; KUSHNIR; GIANNINI, 2002). Conforme Giannini, Kushnir e Cane (2000), durante os eventos quentes do ENOS as anomalias positivas de pressão ao nível do mar na região da ZCIT do Atlântico induzem a redução do gradiente meridional de pressão entre a ZCIT do Atlântico e o Anticiclone Subtropical do Atlântico Norte, enfraquecendo os alísios de nordeste. Esse enfraquecimento induz a anomalias positivas de TSM no Atlântico Norte tropical e à configuração do Dipolo do Atlântico. Rodrigues et al. (2011) mostram que eventos de El Niño com maior aquecimento da TSM no Pacífico Leste (central) geram anomalias negativas (positivas) de TSM na região da Corrente de Benguela e Atlântico equatorial. Quando as anomalias de TSM no Atlântico Sul tropical e Leste equatorial são negativas (positivas), o gradiente meridional de TSM ao longo do equador é positivo (negativo), desfavorecendo (favorecendo) o deslocamento para sul da ZCIT do Atlântico, o que resulta em anomalias negativas (positivas) de precipitação sobre a região Nordeste do Brasil (RODRIGUES et al, 2011).

Uvo et al. (1998) e Silva e Kousky (2012) analisam a relação entre a TSM no Atlântico tropical, a ZCIT do Atlântico e a precipitação na região Nordeste do Brasil. Os autores mostram que o padrão do Dipolo do Atlântico resulta em um deslocamento anômalo do cavado equatorial e da ZCIT do Atlântico: eventos secos (chuvosos) na região Nordeste do Brasil são acompanhados por anomalias positivas (negativas) de TSM ao norte do equador, anomalias negativas (positivas) ao sul e a ZCIT do Atlântico deslocada anomalamente para norte (sul). Por meio de análise de correlação linear entre a TSM no Atlântico tropical e a precipitação na América do Sul, através dos índices Tropical Southern Atlantic (TSA) e Tropical Northern Atlantic (TNA), Kayano, Oliveira e Andreoli (2009) observam que no período de 1948 a 1976 existe correlação positiva entre o índice TSA e a precipitação na região Nordeste do Brasil, bem como correlação negativa no extremo leste da região Sudeste. Não existe correlação com o índice TNA. Por outro lado, os autores mostram que no 
período de 1977 a 2002 há correlação positiva entre o índice TSA e a precipitação no norte da América do Sul, incluindo o centro-oeste da região Nordeste e leste da região Norte do Brasil; e correlação negativa com orientação noroeste-sudeste entre o norte da Bolívia e o sudeste do Paraguai. Correlação negativa é observada entre o índice TNA e a precipitação no norte da América do Sul, incluído o norte da região Nordeste e região Norte do país (KAYANO; OLIVEIRA; ANDREOLI, 2009). Os autores atribuem as diferenças espaciais de correlação entre o índice TSA e a precipitação na América do Sul nos períodos de 1948-1976 e 1977-2002 às teleconexões entre o ENOS e o índice TSA, enquanto as diferenças entre o índice TNA e a precipitação nos dois períodos são atribuídas à Alta da Bolívia.

A relação entre anomalias de TSM no Atlântico Sul e a atividade convectiva da ZCAS foi investigada por Chaves e Nobre (2004). Os autores mostram que anomalias positivas (negativas) de TSM no Atlântico Sul tendem a intensificar (enfraquecer) a ZCAS. Com a intensificação da ZCAS, existe um aumento da nebulosidade e redução da radiação solar incidente, o que resulta em resfriamento da TSM no Atlântico Sul (CHAVES; NOBRE, 2004). Avaliando o impacto da TSM no Atlântico Sul e da ZCAS na variabilidade interanual da precipitação no sudeste da América do Sul durante o verão, Barros et al. (2000) observam que anomalias de TSM negativas (positivas) entre $20^{\circ} \mathrm{S}-40^{\circ} \mathrm{S}$ e a oeste de $30^{\circ} \mathrm{W}$ estão associadas a um deslocamento para norte (sul) da ZCAS e anomalias positivas (negativas) de precipitação no sudeste da América do Sul. Os autores mostram que o deslocamento latitudinal e a intensidade da ZCAS não são independentes, uma vez que existe uma tendência da ZCAS ser fraca quando deslocada para sul.

Bombardi et al. (2014) observam que o acoplamento oceano-atmosfera no Dipolo do Atlântico Sul, o qual é caracterizado como um dipolo de anomalias de TSM com centros no Atlântico Sul tropical e extratropical (VENEGAS; MYSAK; STRAUB, 1997; HAARSMA, 2003; STERL; HAZELEGER, 2003), influencia significativamente a organização da ZCAS, afetando a posição e movimento dos ciclones extratropicais. Os autores mostram que na fase negativa do Dipolo do Atlântico Sul, caracterizada por anomalias negativas de TSM no Atlântico Sul tropical, anomalias positivas no Atlântico Sul extratropical e anomalias positivas de pressão ao nível do mar sobre todo o Atlântico Sul, existe um aumento na ciclogênese e alta densidade de trajetórias de ciclones na costa sudeste do Brasil, resultando em aumento da precipitação sobre o leste da América do Sul, que inclui o Estado de MG, o que parece estar associado com a organização da ZCAS.

Extremos de precipitação na região Sudeste do Brasil associados a anomalias de TSM no Atlântico Sul foram investigados por Pampuch et al. (2016). Os autores mostram que eventos extremos secos nos estados de São Paulo, Rio de Janeiro e centro-sul de MG, entre o outono e a primavera, estão associados a um padrão de tripolo (negativo, positivo e negativo) de anomalias de TSM no Atlântico Sul, juntamente com uma circulação anticiclônica anômala, transportando umidade para o sul do Brasil, associada com anomalias positivas de TSM. Eventos extremos secos no Espírito Santos e norte/leste de MG durante o outono e inverno também estão associados a um padrão de tripolo de anomalias de TSM no Atlântico Sul, porém deslocado para norte e associado a um ciclone anômalo sobre as anomalias negativas de TSM (PAMPUCH et al., 2016). 
Diante do exposto fica evidente a relação entre as anomalias de TSM no Atlântico e a precipitação no Brasil, embora estudos enfocando as anomalias de TSM no Atlântico tropical e a precipitação no estado de MG sejam escassos. Assim, o objetivo deste estudo foi investigar a atividade convectiva associada às anomalias de TSM no Atlântico tropical, bem como o padrão espacial sazonal de precipitação e temperatura do ar sobre o Brasil, com foco em MG.

\section{MATERIAL E MÉTODOS}

Para a análise das anomalias de TSM no Atlântico tropical foi utilizado o índice Tropical Southern Atlantic (TSA) e Tropical Northern Atlantic (TNA) da National Oceanic and Atmospheric Administration (NOAA, ENFIELD et al., 1999), para o período de dezembro de 1979 a novembro de 2015. Os índices são calculados a partir de anomalias médias mensais de TSM do conjunto de dados Hadley Centre Sea Ice and Sea Surface Temperature (HadISST)/NOAA (NATIONAL CENTER FOR ATMOSPHERIC RESEARCH STAFF, 2016), para o setor do TSA $\left(0^{\circ}-20^{\circ} \mathrm{S}\right.$ e $\left.10^{\circ} \mathrm{E}-30^{\circ} \mathrm{W}\right)$ e TNA $\left(5,5^{\circ} \mathrm{N}-23,5^{\circ} \mathrm{N}\right.$ e $\left.15^{\circ} \mathrm{W}-57,5^{\circ} \mathrm{W}\right)$. Eventos sazonais quentes (frios) do TSA/TNA foram definidos como índices acima (abaixo) de um desvio padrão (Figura 1). O número de eventos independentes de eventos sazonais frios/quentes do TSA/TNA pode ser observado na Figura 2.

(a)

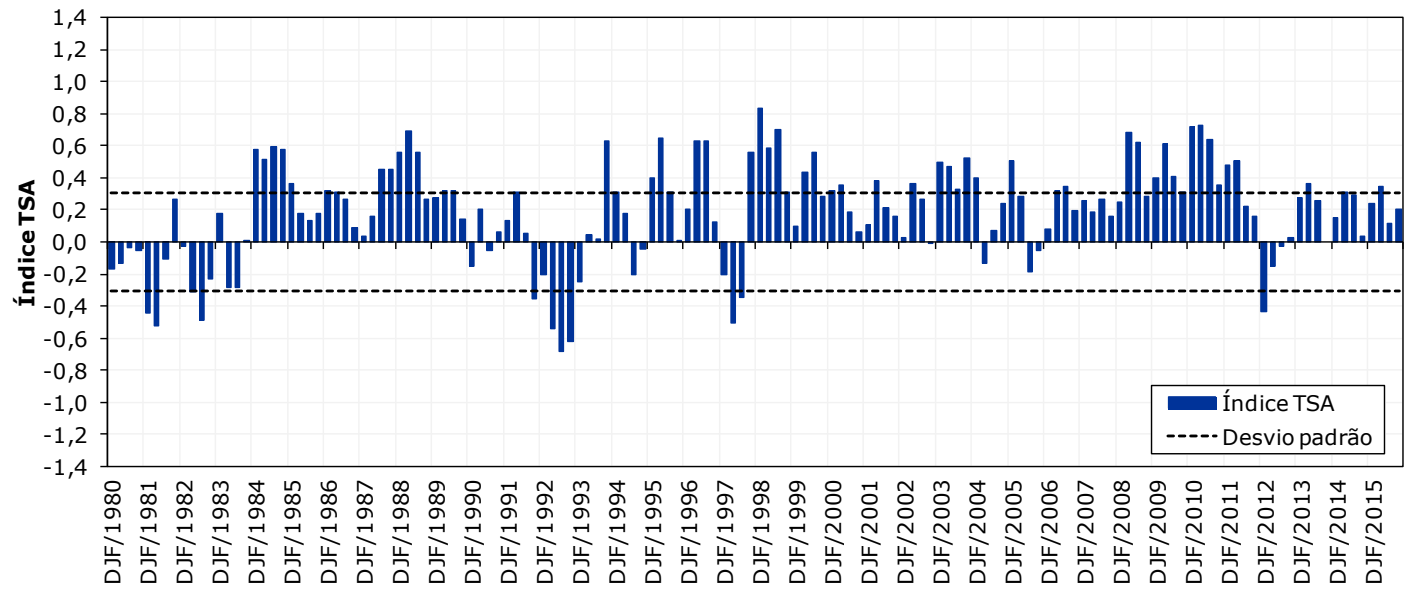

Figura 1 - Índice (a) TSA e (b) TNA sazonal e respectivos desvios padrões entre DJF/1980 e SON/2015. 
(b)

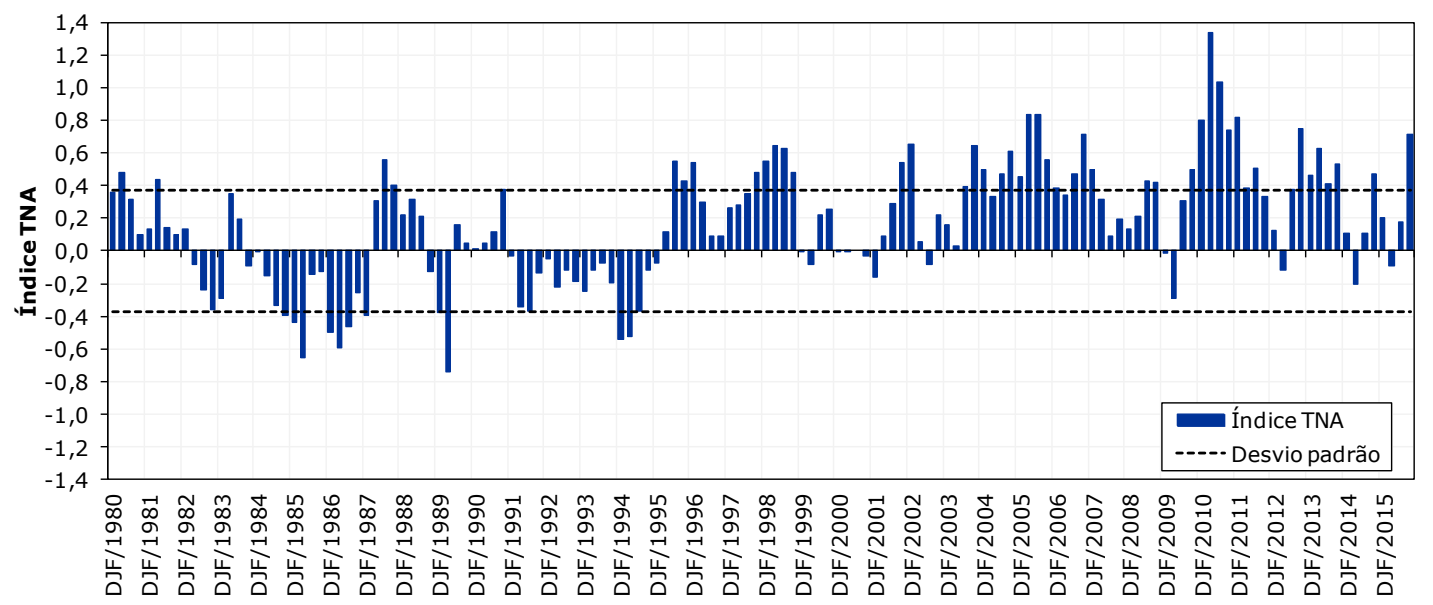

Figura 1 - Continuação.

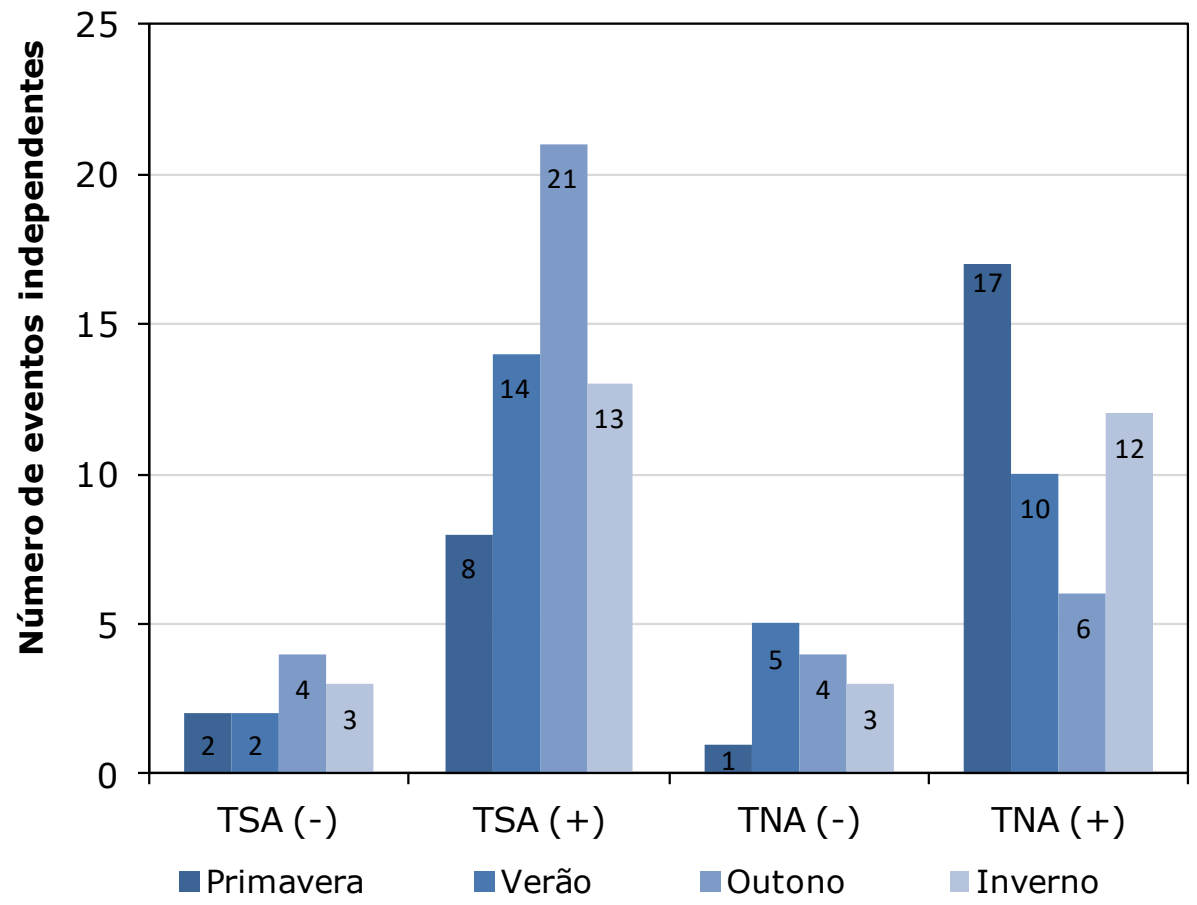

Figura 2 - Número de eventos independentes de eventos sazonais frios do TSA [TSA $(-)]$, quentes do TSA [TSA $(+)]$, frios do TNA [TNA (-)] e quentes do TNA [TNA $(+)]$.

A série temporal mensal de TSM, versão ERSST.v3b (SMITH et al, 2008), foi obtida do Climate Prediction Center da NOAA. Extended Reconstructed Sea Surface Temperature (ERSST) é um conjunto de dados global de TSM mensal derivado do International Comprehensive Ocean-Atmosphere Dataset com falhas preenchidas por métodos estatísticos. A versão 3 (v3b) não inclui dados de satélite, os quais foi verificado resultarem em um viés frio significativo à TSM (SMITH et al, 2008). 
A série temporal diária de radiação de onda longa emergente (ROLE) foi obtida da NOAA, com uma grade global de $2,5^{\circ}$ de latitude $\times 2,5^{\circ}$ de longitude (LIEBMANN; SMITH, 1996). Originalmente os dados de ROLE são oriundos do NCAR (National Center for Atmospheric Research), em que as falhas são preenchidas através de interpolação espacial e temporal. Para detalhes sobre a técnica de interpolação ver Liebmann e Smith (1996).

A série temporal diária de precipitação foi obtida da base de dados de alta resolução desenvolvida por Xavier, King e Scanlon (2016) e atualizada em Xavier, King e Scanlon (2017). Os autores usaram dados de precipitação de aproximadamente 9.259 pluviômetros para criar um conjunto de dados em ponto de grade, com espaçamento horizontal de $0,25^{\circ}$ de latitude $\times 0,25^{\circ}$ de longitude. Os dados dos pluviômetros foram obtidos da Agência Nacional de Águas (ANA), do Instituto Nacional de Meteorologia (INMET), do Departamento de Águas e Energia Elétrica do Estado de São Paulo e da Superintendência do desenvolvimento do Nordeste (SUDENE) (XAVIER; KING; SCANLON, 2017).

O campo de temperatura do ar a $2 \mathrm{~m}$ foi obtido das reanálises do ERAInterim (European Centre for Medium-Range Weather Forecasts - ECMWF Data Server). ERA-Interim é uma reanálise atmosférica global produzida pelo ECMWF, desenvolvida para corrigir alguns erros da reanálise ERA-40, particularmente em relação à representação do ciclo hidrológico (UPPALA et al., 2008), à qualidade da circulação estratosférica e à contaminação de sinais climáticos por mudanças no sistema de observação (DEE, 2005; BENGTSSON et al., 2007). Nas reanálises do ERA-Interim a assimilação de dados produz parâmetros em superfície e em 37 níveis de pressão, sendo o nível superior em 0,1 hPa (BERRISFORD et al., 2009), com espaçamento horizontal de $1,5^{\circ}$ de latitude $x$ $1,5^{\circ}$ de longitude.

Foram feitas composições espaciais de TSM, ROLE, precipitação e temperatura do ar a $2 \mathrm{~m}$ durante os eventos sazonais quentes e frios do TSA/TNA. Posteriormente, as composições foram subtraídas da média climatológica sazonal (1981-2010), gerando campos espaciais anômalos durante os eventos sazonais quentes e frios do TSA/TNA. A significância estatística das anomalias foi obtida através do teste t-Student, ao nível de $10 \%$.

\section{RESULTADOS E DISCUSSÃO}

\subsection{EVENTOS FRIOS DO TSA}

Os resultados mostram que durante os eventos frios do TSA há anomalias negativas de TSM no Atlântico Sul tropical, estendendo em direção ao Atlântico Sudeste, na costa oeste da África, e anomalias positivas no Atlântico extratropical (Figuras 3a-d). Este padrão anômalo ocorre em todas as estações do ano e é muito similar ao Dipolo do Atlântico Sul (VENEGAS; MYSAK; STRAUB, 1997; HAARSMA, 2003; STERL; HAZELEGER, 2003; BOMBARDI et al., 2014). O resfriamento anômalo da TSM no Atlântico Sul tropical favorece o deslocamento anômalo da ZCIT do Atlântico para norte de sua posição climatológica, como pode ser observado através das anomalias positivas de ROLE (supressão de convecção anômala) no Atlântico próximo ao equador e anomalias negativas (convecção anômala) no Atlântico Norte tropical (Figuras 3e-h). Da mesma forma, convecção anômala ocorre no Atlântico Sul tropical: na primavera e outono ocorre no Atlântico Sul, entre cerca de $10^{\circ} \mathrm{S}$ e $30^{\circ} \mathrm{S}$ (Figuras $3 \mathrm{e}, 3 \mathrm{~g}$ ), e 
durante o inverno no leste do Atlântico tropical, centrado em torno de $10^{\circ} \mathrm{S}$ (Figura 3h).

$\mathrm{Na}$ primavera, verão e outono existe um padrão espacial de dipolo de anomalias de precipitação sobre o Brasil, com anomalias negativas na região Sul e anomalias positivas com orientação noroeste-sudeste entre o sudeste do Amazonas e os estados de São Paulo, Rio de Janeiro e Espírito Santo (Figuras $4 a-c$ superiores). Desta forma, em MG há predomínio de anomalias positivas de precipitação na primavera e verão (Figuras 4a, 4b inferiores), com desvios de até $+200 \mathrm{~mm}$ nas mesorregiões Noroeste de Minas, Norte de Minas, norte de Central Mineira, Metropolitana de Belo Horizonte, leste de Oeste de Minas, Sul e Sudoeste de Minas, Campo das Vertentes e oeste da Zona da Mata. No outono não há significância estatística nas anomalias de precipitação no Estado de MG (Figura 4c inferior).

Essa organização espacial das anomalias de precipitação sobre o Brasil é o padrão de gangorra associado à atividade convectiva da ZCAS anteriormente documentado em alguns estudos (e.g., CASARIN; KOUSKY, 1986; NOGUÉSPAEGLE; MO, 1997; MUZA et al., 2009). Essa relação pode ser explicada como parte de fases distintas da propagação de trens de ondas de latitudes médias, ligados a distúrbios intrassazonais tropicais, e de trens de ondas de escala sinótica, associados à propagação de frentes frias e ciclones extratropicais até latitudes mais baixas acompanhada de reforço da atividade convectiva (LIEBMANN et al., 1999; CARVALHO; JONES; LIEBMANN, 2004; MARENGO et. al, 2004; MUZA et al., 2009; BOMBARDI et al., 2014).

Assim como observado na região Sul do país entre a primavera e o outono, na região Norte/noroeste do Nordeste também há anomalias negativas de precipitação (Figuras 4a-c superiores), com desvios de até $-150 \mathrm{~mm}$ no Maranhão e Piauí durante o outono. Esses resultados estão de acordo com estudos prévios, relacionando precipitação e anomalias de TSM no Atlântico tropical (e.g., RODRIGUES et al, 2011; KAYANO; OLIVEIRA; ANDREOLI, 2009; NOBRE; SHUKLA, 1996). Variações na precipitação na região Nordeste do Brasil estão associadas com a posição da ZCIT no Atlântico, a qual apresenta posição mais ao sul durante o outono em relação às demais estações do ano. Estudos mostram que a ZCIT do Atlântico é impedida de migrar para sul em anos com anomalias negativas de TSM no Atlântico Sul tropical e anomalias positivas no Atlântico Norte tropical, pois a ZCIT é deslocada em direção às águas quentes, resultando em chuvas abaixo da média na região Nordeste do país (NOBRE; SHUKLA, 1996; UVO et al., 1998; RODRIGUES et al, 2011; SILVA; KOUSKY, 2012).

Durante o inverno há anomalias positivas de precipitação na região Sul do Brasil, entre o sudoeste de Santa Catarina e extremo norte do Rio Grande do Sul, com anomalias de até $+100 \mathrm{~mm}$ (Figura 4d superior). Por outro lado, anomalias negativas de precipitação ocorrem na região Nordeste e norte da região Norte do país, com valores de até $-200 \mathrm{~mm}$ no norte do Amazonas, Roraima e Amapá. Esse padrão provavelmente está associado a uma migração anômala para norte da ZCIT do Atlântico, como pode ser evidenciado através das anomalias de supressão de convecção no Atlântico, entre cerca de $5^{\circ} \mathrm{S}$ e $5^{\circ} \mathrm{N}$, e convecção anômala no Atlântico Norte tropical (Figura 3h). No Estado de MG há anomalias negativas de precipitação de até $-25 \mathrm{~mm}$ nas mesorregiões Norte de Minas e Jequitinhonha (Figura 4d inferior). 
Com o aumento da precipitação nas regiões Sudeste e Centro-Oeste do Brasil, na primavera e verão são observadas anomalias negativas de temperatura do ar (Figuras $5 a, 5 b$ superiores). Da mesma forma, em praticamente todo o Estado de MG há resfriamento anômalo de até $1,0^{\circ} \mathrm{C}$ na primavera (Figura 5a inferior): mesorregiões do Triângulo Mineiro e Alto Paranaíba, Noroeste de Minas, Norte de Minas, Central Mineira, Jequitinhonha, Vale do Rio Doce e Metropolitana de Belo Horizonte; e de até $-0,8^{\circ} \mathrm{C}$ no verão (Figura 5b inferior): mesorregiões do Norte de Minas, Jequitinhonha, Vale do Mucuri, Vale do Rio Doce, Metropolitana de Belo Horizonte e Central Mineira.

No outono há resfriamento anômalo no leste da Bahia, norte do Espírito Santo e Goiás (Figura $5 c$ superior). Em MG há anomalias negativas nas mesorregiões do Jequitinhonha e Norte de Minas, Vale do Mucuri e Triângulo Mineiro e Alto Paranaíba, com desvios de até $1,0^{\circ} \mathrm{C}$ (Figura $5 \mathrm{c}$ inferior). No inverno há resfriamento anômalo no sudoeste de Tocantins (Figura $5 \mathrm{~d}$ superior). Em MG não há anomalias com significância estatística (Figura 5d inferior).

PRIMAVERA

(a)

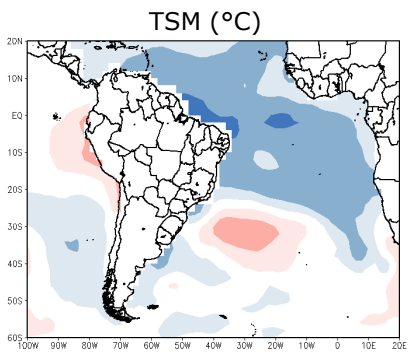

(e)

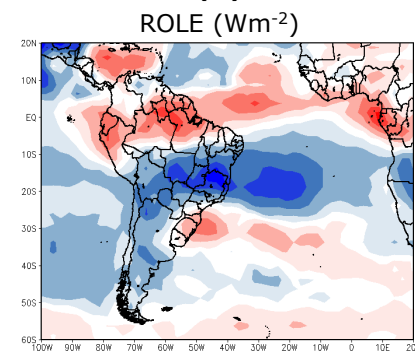

VERÃO

(b)

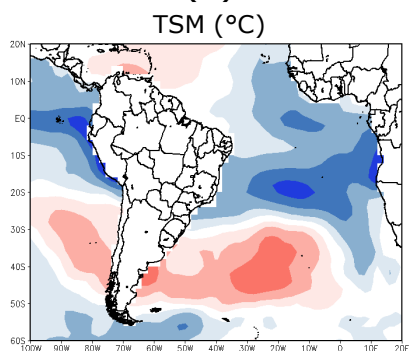

(f)

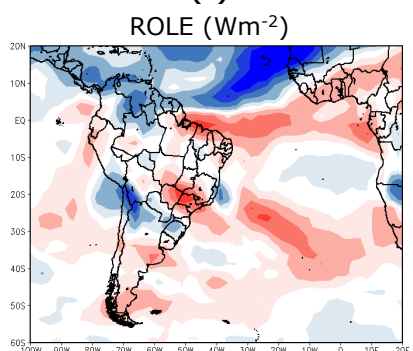

OUTONO

(c)

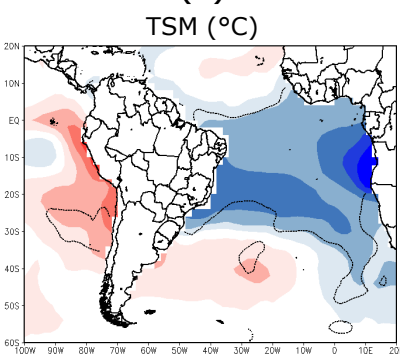

(g)

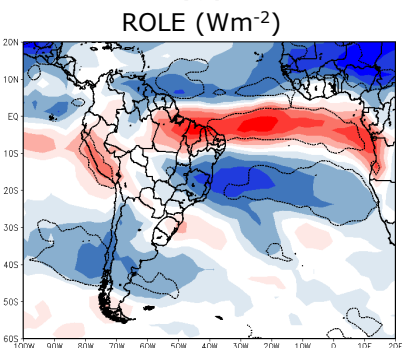

INVERNO

(d)

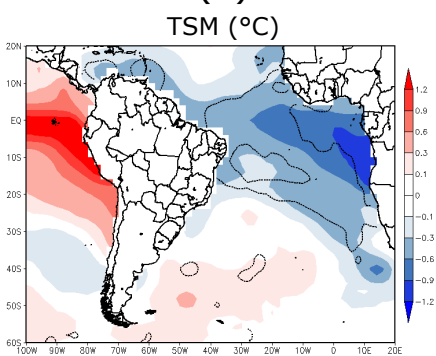

(h)

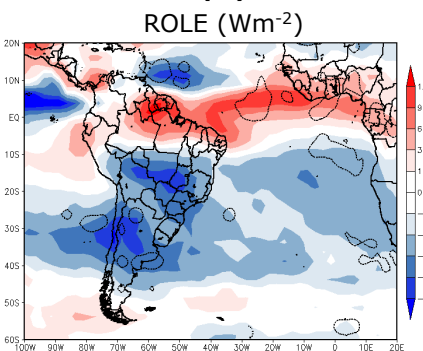

Figura 3 - Composições na (a, e) primavera, $(b, f)$ verão, $(c, g)$ outono e $(d, h)$ inverno de anomalias de temperatura da superfície do mar (TSM) e radiação de onda longa emergente (ROLE), respectivamente, durante os eventos frios do TSA. Linhas pontilhadas indicam anomalias significativas ao nível de $10 \%$. 
PRIMAVERA

(a)
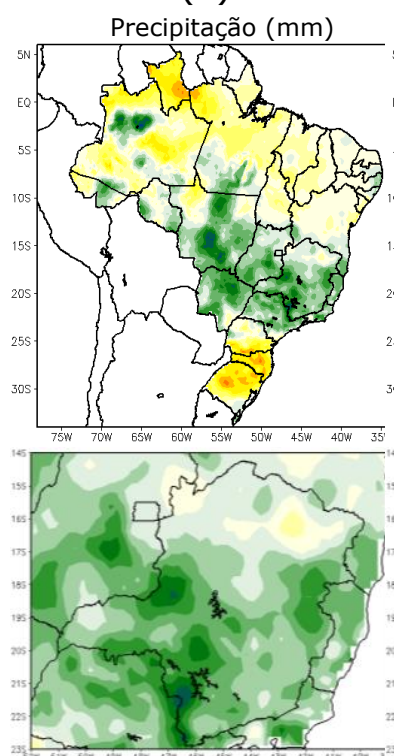

VERÃO

(b)
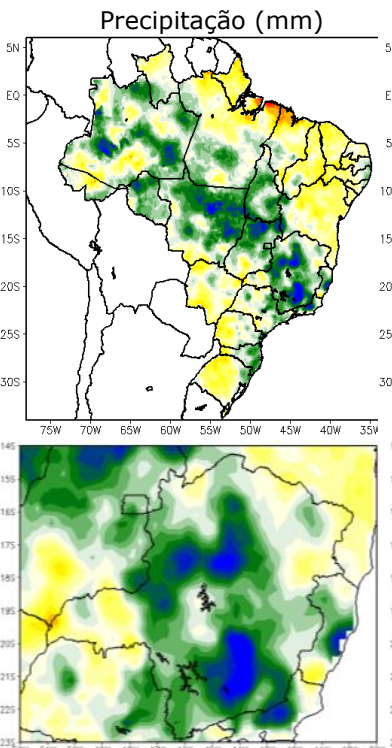

OUTONO

(c)
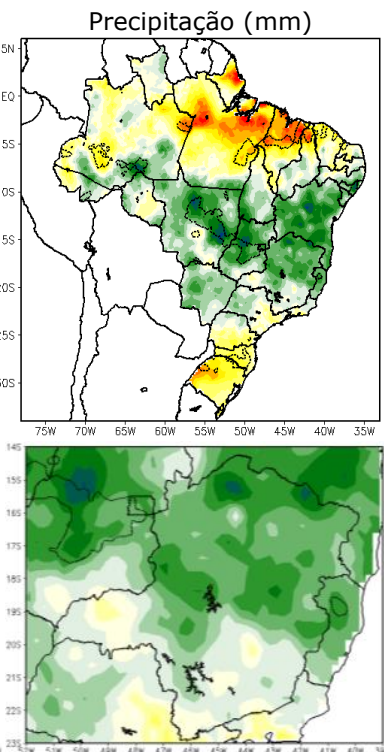

INVERNO

(d)
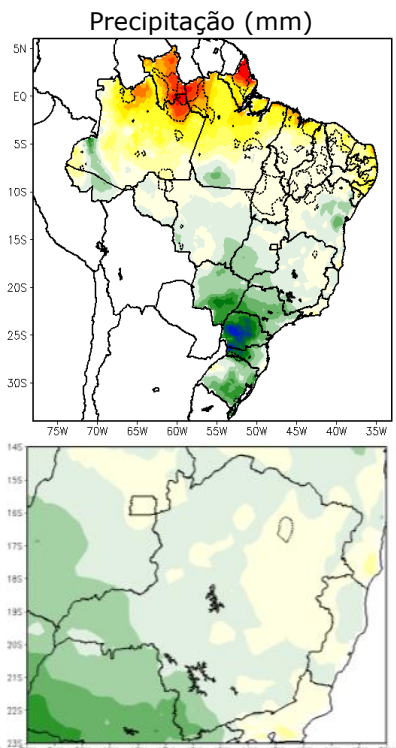

Figura 4 - Composições de anomalias de precipitação na (a) primavera, (b) verão, (c) outono e (d) inverno sobre o Brasil (figuras superiores) e o Estado de Minas Gerais (figuras inferiores) durante os eventos frios do TSA. Linhas pontilhadas indicam anomalias significativas ao nível de $10 \%$.

PRIMAVERA

(a)

Temperatura do $\operatorname{ar}\left({ }^{\circ} \mathrm{C}\right)$
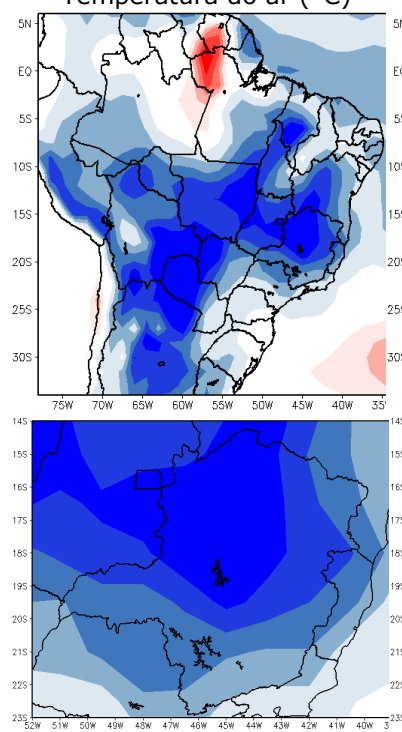

VERÃO

(b)
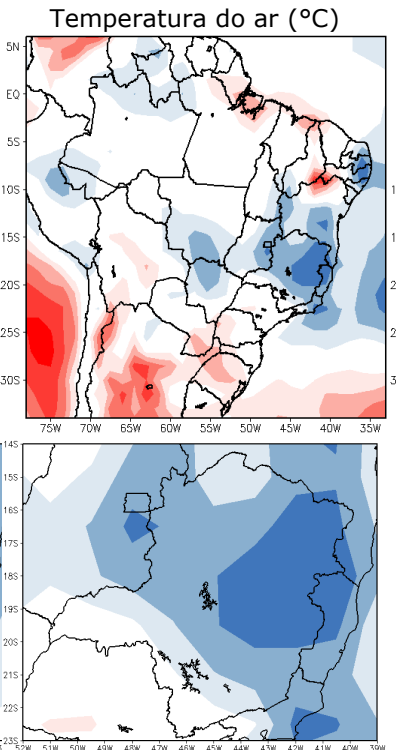

OUTONO

(c)

Temperatura do ar $\left({ }^{\circ} \mathrm{C}\right)$
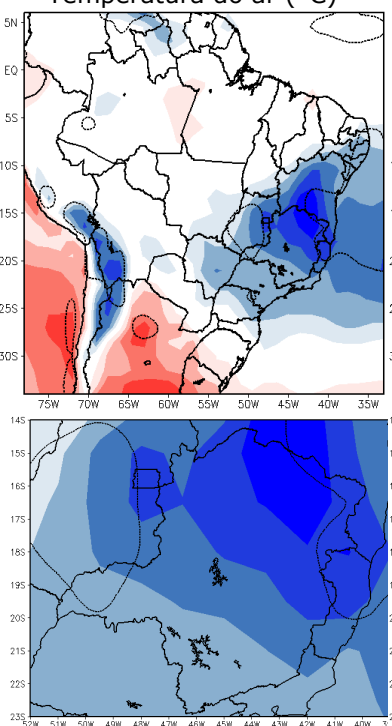

INVERNO

(d)

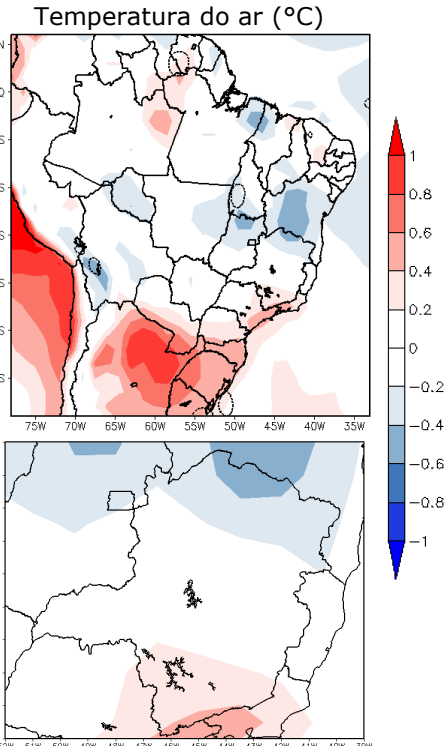

Figura 5 - Composições de anomalias de temperatura do ar a 2 m na (a) primavera, (b) verão, (c) outono e (d) inverno sobre o Brasil (figuras superiores) e o Estado de Minas Gerais (figuras inferiores) durante os eventos frios do TSA. Linhas pontilhadas indicam anomalias significativas ao nível de $10 \%$. 


\subsection{EVENTOS QUENTES DO TSA}

Um padrão de anomalias relativamente oposto é observado em eventos quentes do TSA em relação aos eventos frios. As anomalias de TSM no Atlântico Sul tropical são positivas em todas as estações do ano (Figuras 6a-d), enquanto anomalias negativas são observadas nas latitudes extratropicais do Atlântico Sul somente no verão e inverno. Em relação à atividade convectiva, o padrão espacial é de convecção anômala em torno do equador e supressão de convecção anômala no Atlântico Norte tropical e Atlântico Sul tropical e extratropical (Figuras 6e-h), uma vez que a ZCIT do Atlântico é deslocada em direção às águas quentes (NOBRE; SHUKLA, 1996; UVO et al., 1998; RODRIGUES et al, 2011; SILVA; KOUSKY, 2012).

Na primavera a supressão de convecção anômala está posicionada entre o equador e $20^{\circ} \mathrm{S}$, estendendo sobre o leste da região Nordeste do Brasil (Figura 6e). Desta forma, são observadas anomalias negativas de precipitação no extremo leste da região Nordeste, além de algumas regiões pontuais, como no sul do Mato Grosso, centro de Roraima, extremo norte do Amazonas e oeste de Roraima, enquanto anomalias positivas ocorrem no sul e sudoeste do Mato Grosso do Sul (Figura 7a superior). No estado de MG não há anomalias com significância estatística (Figura 7a inferior).

No verão são observadas anomalias positivas de precipitação no norte da região Nordeste, sudeste do Pará e sudoeste do Mato Grosso, enquanto anomalias negativas ocorrem com orientação noroeste-sudeste entre o Acre/Amazonas e São Paulo/norte do Paraná, com valores de até $-75 \mathrm{~mm}$ no oeste do Acre e sudoeste do Amazonas (Figura 7b superior). Em MG não há anomalias com significância estatística (Figura 7b inferior). Este padrão espacial de anomalias de precipitação sobre o Brasil é semelhante ao encontrado por Muza et al. (2008), em que observam que condições de eventos extremos secos na região Sudeste do país favorecem anomalias positivas de precipitação na região Norte e Nordeste associadas à uma ZCIT ativa no Atlântico na escala interanual. Kayano, Oliveira e Andreoli (2009) encontram um padrão de correlação negativa entre a precipitação e o índice TSA no período de 1977 e 2002, com orientação noroeste-sudeste entre o norte da Bolívia e o sudeste do Paraguai, enquanto a correlação é positiva em parte da região Norte e Nordeste do Brasil.

No outono, a convecção anômala nas baixas latitudes se estende em direção ao oeste da região Nordeste do Brasil, leste e extremo sudoeste da região Norte, além do norte do Mato Grosso (Figura 6g). Desta forma, são observadas anomalias positivas de precipitação nestas regiões, além do Mato Grosso do Sul, com valores de até $+100 \mathrm{~mm}$ no Pará (Figura 7c superior). No oeste do Amazonas, onde há supressão de convecção anômala, se observa anomalias negativas de precipitação de até $-75 \mathrm{~mm}$. Em MG há redução de precipitação de até $-50 \mathrm{~mm}$ nas mesorregiões Zona da Mata, Central Mineira e Jequitinhonha (Figura 7c inferior).

No inverno existe um padrão de supressão de convecção anômala entre o sul de Rondônia em direção ao sul da região Sudeste e norte da região Sul (Figura 6h), muito semelhante ao padrão espacial de correlação negativa entre a precipitação e o índice TSA encontrado por Kayano, Oliveira e Andreoli (2009). Assim, há anomalias negativas de precipitação na região Sul, Sudeste, CentroOeste, centro-sul da região Nordeste e sul do Pará, com valores de até $75 \mathrm{~mm}$ em Santa Catarina (Figura 7d superior). Anomalias positivas são observadas no 
norte da região Norte do país, com valores de até $+100 \mathrm{~mm}$ no Amapá. Em MG há anomalias negativas de precipitação de até $-25 \mathrm{~mm}$ em grande parte do Estado, com exceção das mesorregiões Campo das Vertentes, Metropolitana de Belo Horizonte e Zona da Mata (Figura 7d inferior). No inverno a precipitação climatológica em grande parte do Estado varia de 0 a $50 \mathrm{~mm}$ (REBOITA el al., 2015), de forma que as anomalias de precipitação durante os eventos quentes do TSA correspondem a uma redução de 50 a $100 \%$ em relação à climatologia. O padrão espacial de anomalias de TSM associado às anomalias negativas no centro-leste de MG é semelhante ao encontrado por Bombardi et al. (2014), os quais associam a fase positiva do Dipolo do Atlântico Sul e a baixa frequência de ciclones com anomalias negativas de precipitação na América do Sul subtropical.

Em termos de anomalias de temperatura do ar, na primavera há aquecimento no leste da região Nordeste do Brasil, incluindo o estado da Bahia e oeste de Rondônia (Figura 8a superior). Em MG as anomalias positivas são observadas no centro-norte do Estado: mesorregiões da Zona da Mata, Metropolitana de Belo Horizonte, Vale do Rio Doce, Vale do Mucuri, Jequitinhonha, Norte de Minas, Noroeste de Minas e Central Mineira, com anomalias de até $+0,8^{\circ} \mathrm{C}$ (Figura $8 \mathrm{a}$ inferior). Da mesma forma, no verão existe aquecimento anômalo entre o sul do Goiás, sudoeste de MG, oeste de São Paulo, norte do Paraná e leste do Mato Grosso do Sul, além do leste da região Nordeste e norte do Espírito Santo (Figura 8b superior). Em MG aquecimento de até $+0,4^{\circ} \mathrm{C}$ é observado no nordeste do Estado, nas mesorregiões Norte de Minas, Jequitinhonha e Vale do Mucuri, bem como no sudoeste, nas mesorregiões Noroeste de Minas, Triângulo Mineiro e Alto Paranaíba Sul e Sudoeste de Minas (Figura 8b inferior).

No outono as anomalias de temperatura do ar são positivas em grande parte da Bahia e norte de MG (Figura 8c superior), abrangendo as mesorregiões Noroeste de Minas, Norte de Minas, Jequitinhonha e Vale do Mucuri (Figura 8c inferior). No inverno as anomalias positivas ocorrem no sudoeste do Amazonas e entre o nordeste do Pará e noroeste do Maranhão (Figura 8d superior). Não há anomalias com significância estatística em MG (Figura 8d inferior). 


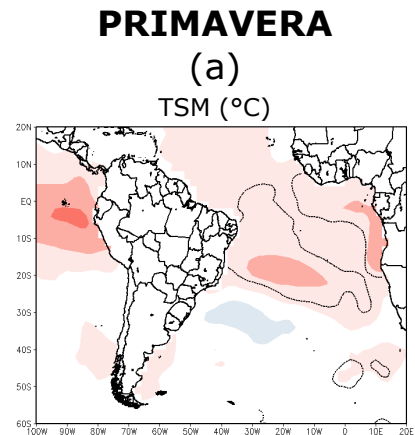

(e)

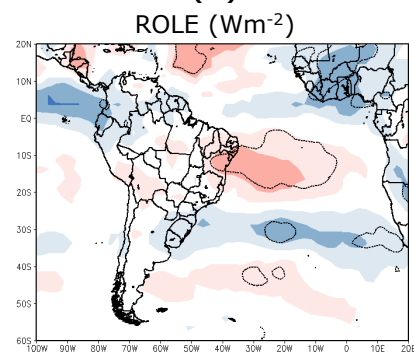

Figura 6 - Similar à Figura 3, mas durante os eventos quentes do TSA.
VERÃO

(b)

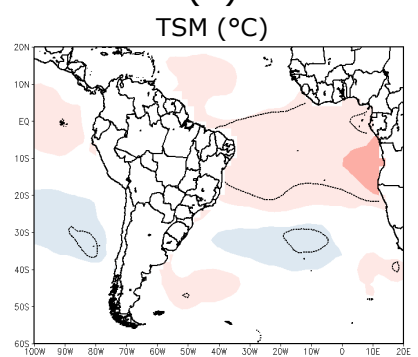

(f)

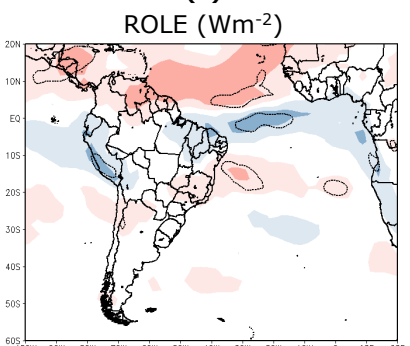

OUTONO

(c)

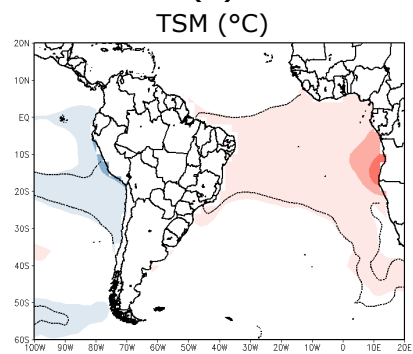

(g)

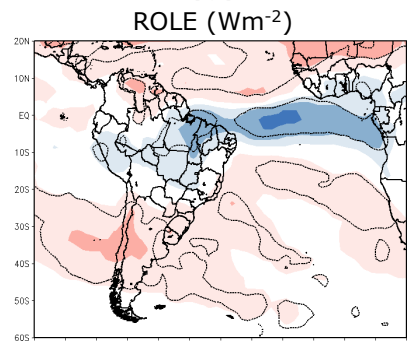

INVERNO

(d)

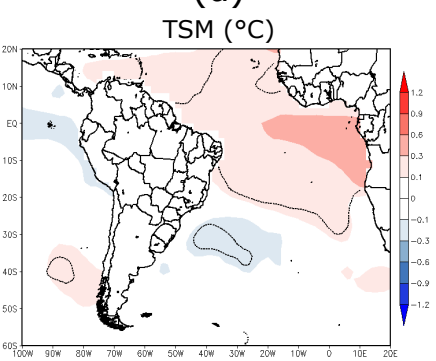

(h)

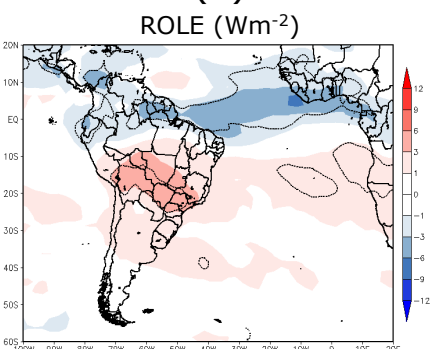

\section{PRIMAVERA}

(a)

Precipitação $(\mathrm{mm})$
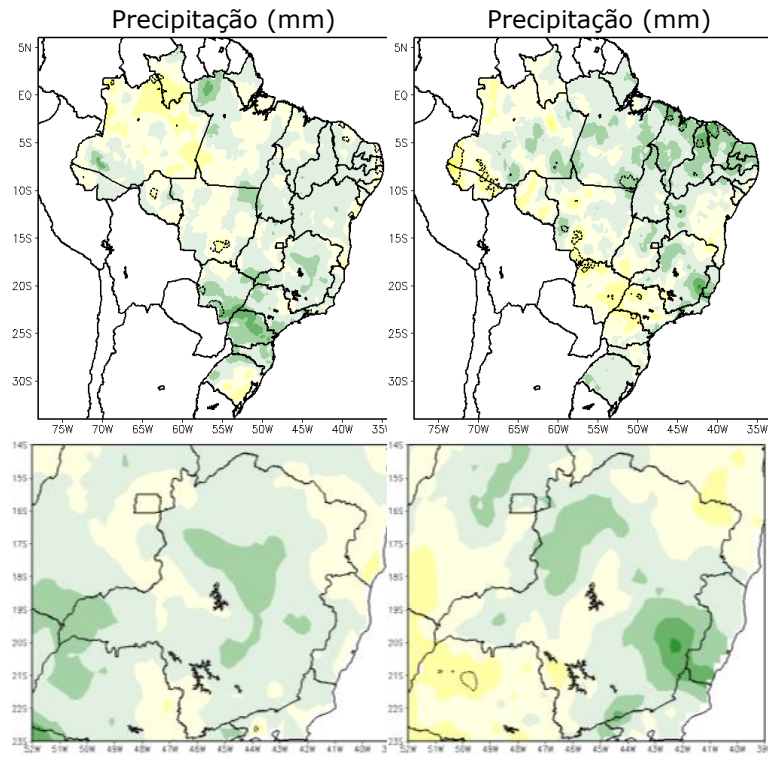

OUTONO

(c)
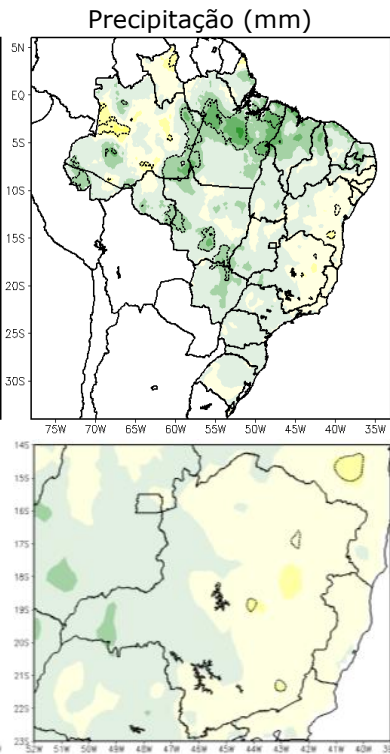

INVERNO

(d)
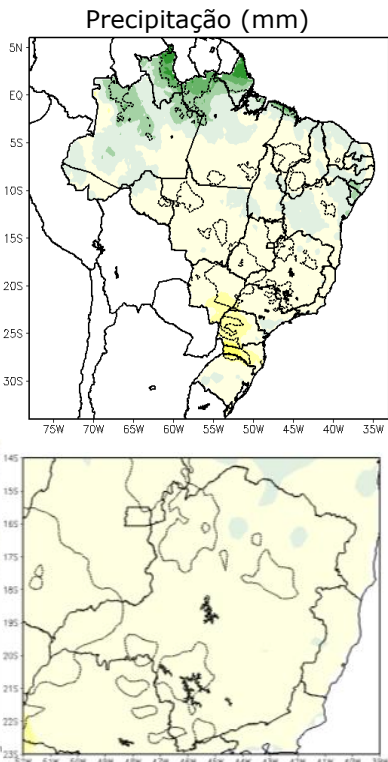

Figura 7 - Similar à Figura 4, mas durante os eventos quentes do TSA. 
PRIMAVERA

(a)

Temperatura do ar $\left({ }^{\circ} \mathrm{C}\right)$
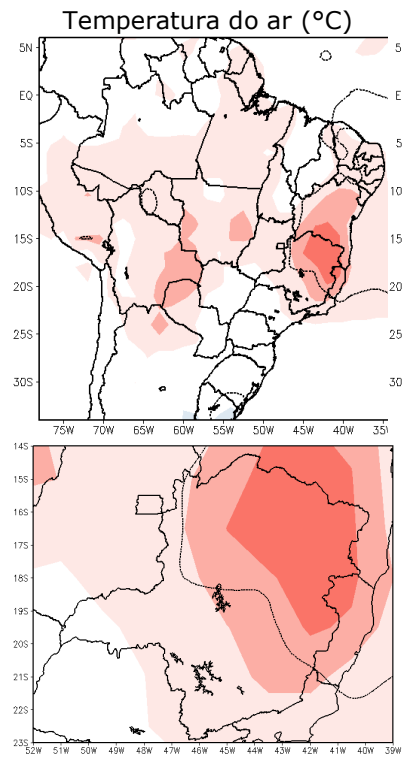

Figura 8 - Similar à Figura 5, mas durante os eventos quentes do TSA
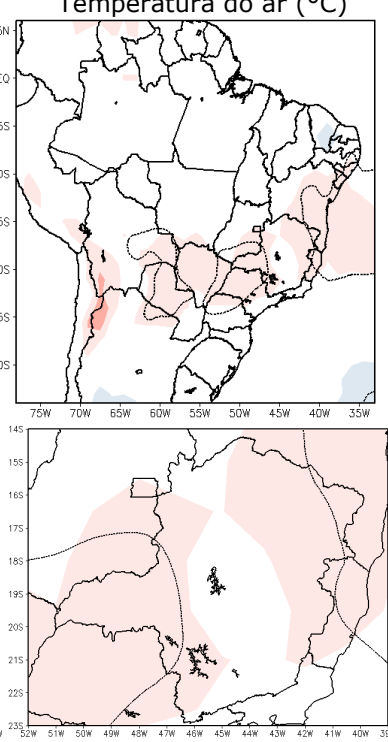

\section{INVERNO}

(d)

(c)

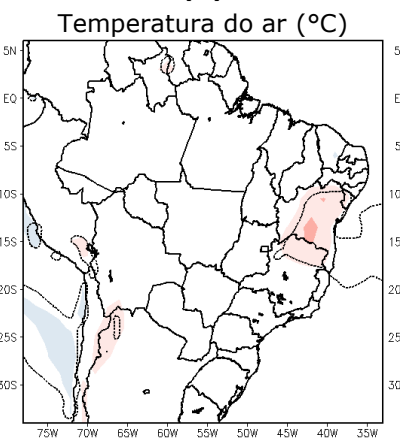

Temperatura do ar $\left({ }^{\circ} \mathrm{C}\right)$

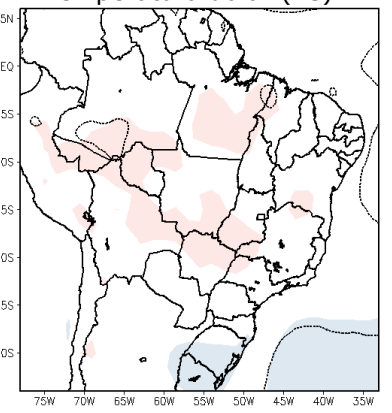

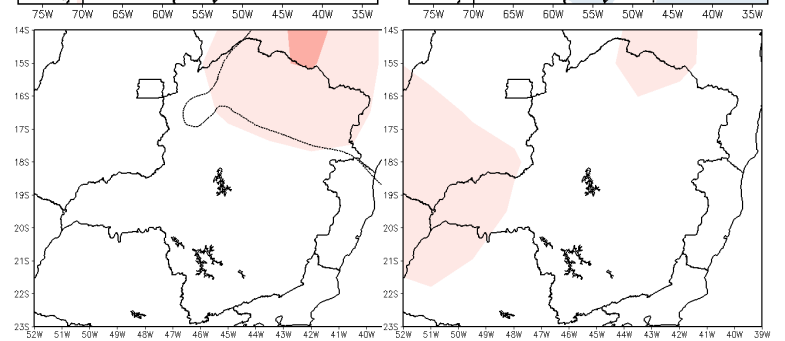

\subsection{EVENTOS FRIOS DO TNA}

Os eventos frios do TNA estão associados com anomalias negativas de TSM no Atlântico Norte tropical em todas as estações do ano (Figuras 9a-d), em direção à costa norte do Brasil (com exceção do outono). Ainda entre a primavera e outono há anomalias positivas no Atlântico Sul tropical. No outono e inverno existe um padrão anômalo de supressão de convecção no Atlântico Norte tropical e convecção no Atlântico Sul tropical, o qual se estende em direção à região Nordeste do país (Figuras 9g, 9h). Essa configuração anômala indica um deslocamento para sul da ZCIT do Atlântico (NOBRE; SHUKLA, 1996; RODRIGUES et al, 2011). Somente no outono é observada convecção anômala com orientação noroeste-sudeste entre o sudoeste do Amazonas e MG, padrão semelhante ao observado por Kayano, Oliveira e Andreoli (2009), o que pode indicar a atividade convectiva associada à ZCAS.

Na primavera há anomalias positivas de precipitação sobre MG, Goiás e Mato Grosso em direção ao norte do Brasil, enquanto ao sul destes estados as anomalias são negativas (Figura 10a superior). Em MG há predomínio de anomalias positivas de precipitação (Figura 10a inferior), com desvios de até +125 mm, com exceção do sul do Estado: mesorregiões do Triângulo Mineiro e Alto Paranaíba, oeste do Noroeste de Minas, oeste de Minas, Sul e Sudoeste de Minas, Campo das Vertentes, Metropolitana de Belo Horizonte e Zona da Mata, com desvios de até $-125 \mathrm{~mm}$. No verão as anomalias positivas de precipitação são observadas no norte do Mato Grosso e região Norte do país, com desvios de até $+200 \mathrm{~mm}$, e anomalias negativas de até $-75 \mathrm{~mm}$ na região Sul (Figura 10b superior). No estado de MG não há anomalias com significância estatística (Figura 10b inferior).

No outono há anomalias positivas de precipitação no noroeste da região Norte, de até $+200 \mathrm{~mm}$, enquanto no centro-sul do Piauí e Bahia são observadas anomalias negativas de até $-75 \mathrm{~mm}$ (Figura 10c superior). Em MG 
há anomalias positivas de precipitação de até $+25 \mathrm{~mm}$ na mesorregião do Jequitinhonha, enquanto no Sul e Sudoeste de Minas há anomalias negativas até -50 mm (Figura 10c inferior). No inverno há anomalias positivas de precipitação no norte da região Nordeste de até $+200 \mathrm{~mm}$, em parte da região Norte, no leste do Pará, sudoeste do Amazonas e Acre, bem como no leste do Rio Grande do Sul e nordeste de Santa Catarina (Figura 10d superior). Por outro lado, anomalias negativas de precipitação são observadas no norte da região Norte do Brasil, com desvios de até $-125 \mathrm{~mm}$. Em MG anomalias positivas de precipitação de $+50 \mathrm{~mm}$ ocorrem na mesorregião do Triângulo Mineiro e Alto Paranaíba, enquanto anomalias negativas de até $-50 \mathrm{~mm}$ ocorrem na mesorregião do Sul e Sudoeste de Minas (Figura 10d inferior).

Em termos de temperatura do ar, na primavera e verão predomina anomalias negativas em grande parte do Brasil nas regiões de anomalias positivas de precipitação, que inclui a região Norte, Centro-Oeste e oeste do Nordeste (Figuras 11a, 11b superiores). Na primavera há resfriamento anômalo também no centro-norte da região Sudeste. Em MG há anomalias negativas de temperatura do ar em praticamente todo o Estado, com exceção das mesorregiões Sul e Sudoeste de Minas, Campo das Vertentes e Zona da Mata (Figura 11a inferior). Em MG anomalias negativas ocorrem no verão entre as mesorregiões Noroeste de Minas, Norte de Minas e Central Mineira (Figura 11b inferior).

No outono anomalias negativas são observadas ao norte de $15^{\circ} \mathrm{S}$, em grande parte das regiões Nordeste, Norte e norte do Centro-Oeste (Figura 11c superior), com anomalias de até $-0,4^{\circ} \mathrm{C}$ em MG nas mesorregiões do Jequitinhonha e Norte de Minas (Figura 11c inferior). Da mesma forma, há anomalias negativas no inverno na região Centro-Oeste, oeste do Norte e centro do Nordeste (Figura 11d superior). Em MG há anomalias negativas de até $-0,6^{\circ} \mathrm{C}$ somente no norte da mesorregião Noroeste de Minas (Figura $11 \mathrm{~d}$ inferior).

PRIMAVERA

(a)

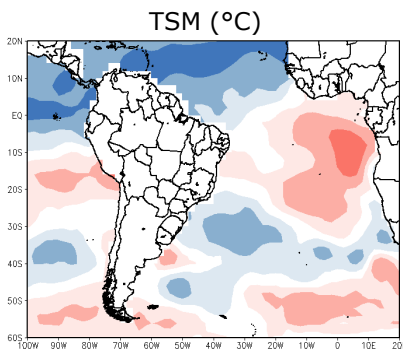

(e)

ROLE $\left(W^{-2}\right)$

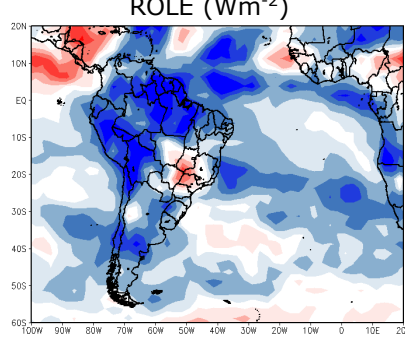

VERÃO

(b)

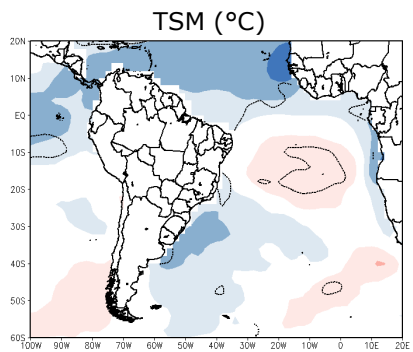

(f)

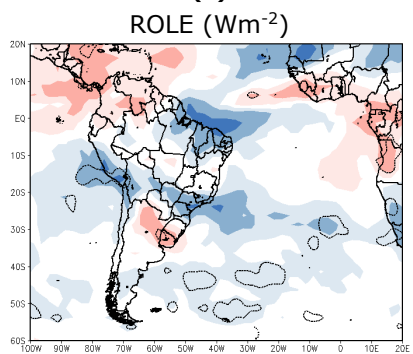

OUTONO

(c)

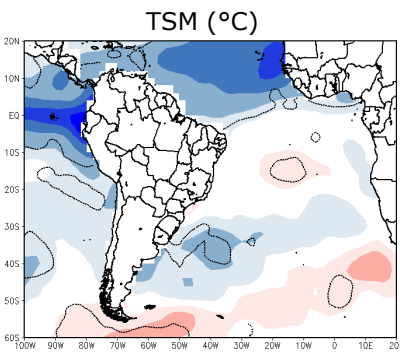

(g)

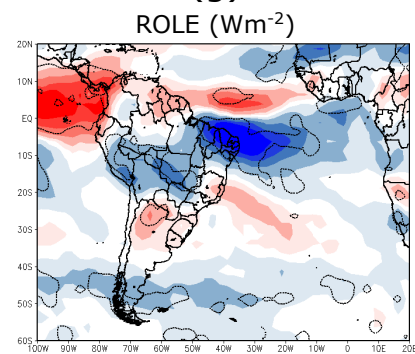

INVERNO

(d)

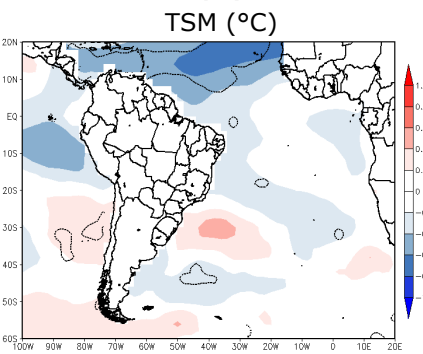

(h)

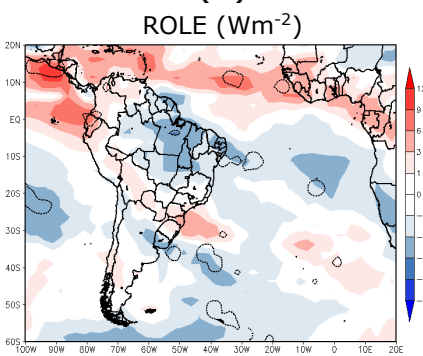

Figura 9 - Similar à Figura 3, mas durante os eventos frios do TNA. 
PRIMAVERA

(a)
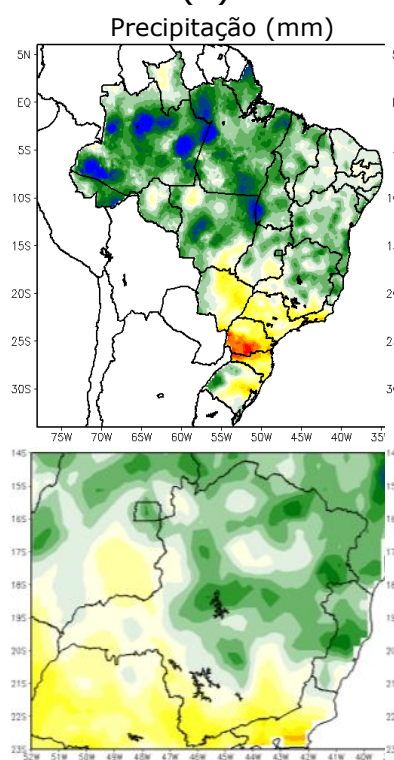

VERÃO

(b)

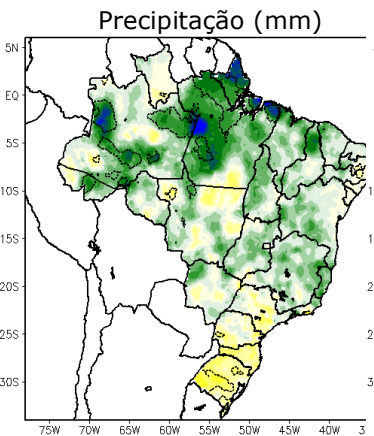

OUTONO

(c)
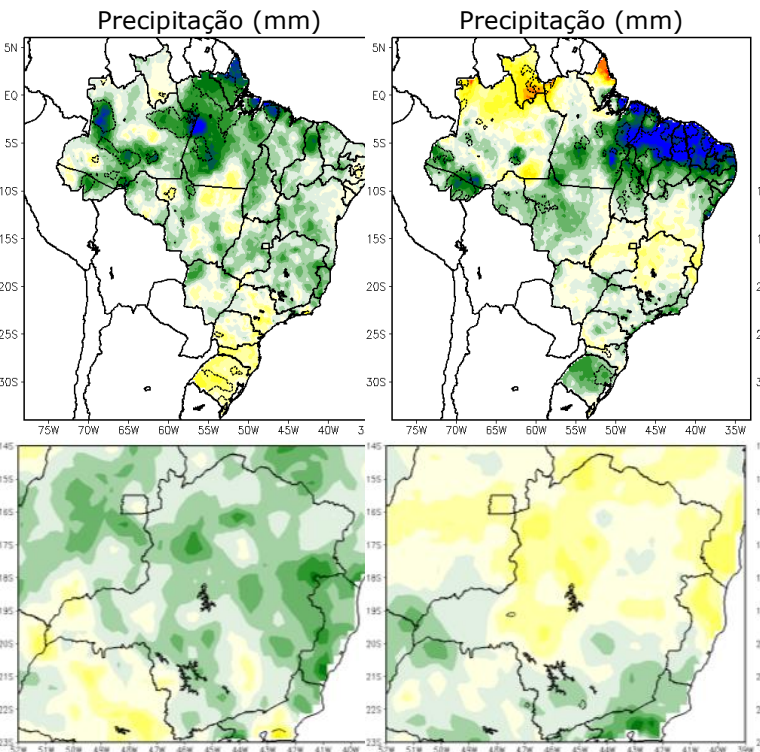

INVERNO

(d)
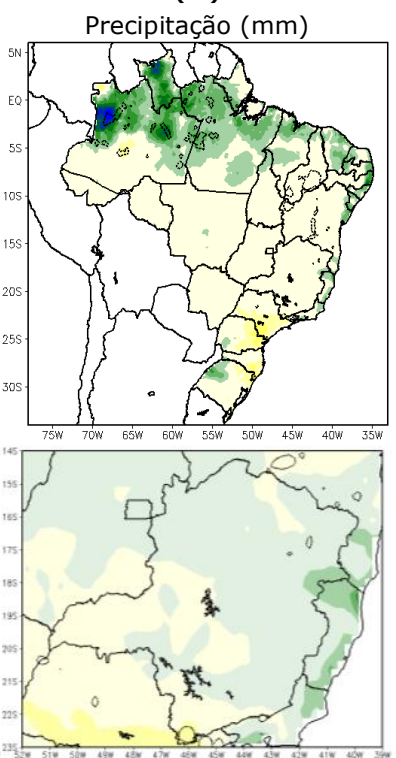

Figura 10 - Similar à Figura 4, mas durante os eventos frios do TNA.

\section{PRIMAVERA}

(a)

Temperatura do ar $\left({ }^{\circ} \mathrm{C}\right)$
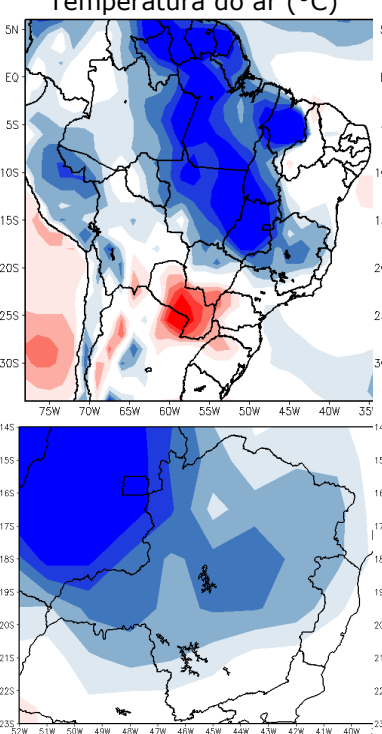

VERÃO

(b)
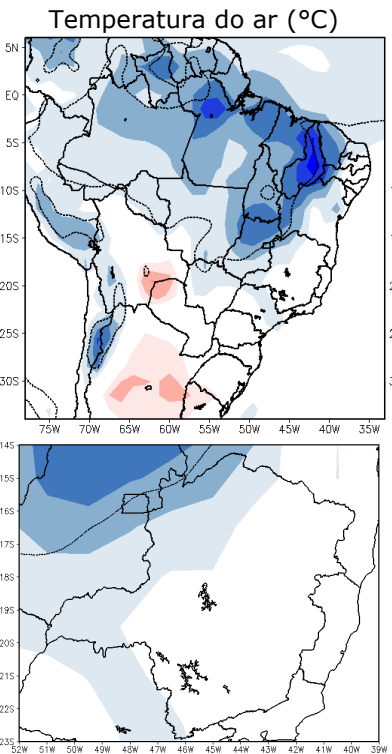

OUTONO

(c)

Temperatura do $\operatorname{ar}\left({ }^{\circ} \mathrm{C}\right)$
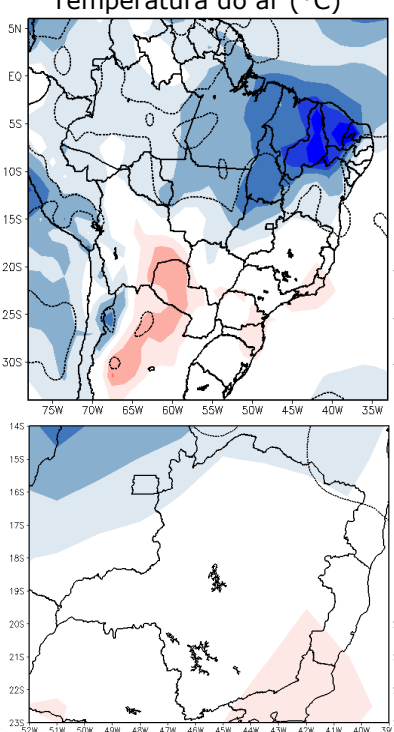

INVERNO

(d)

Temperatura do $\operatorname{ar}\left({ }^{\circ} \mathrm{C}\right)$
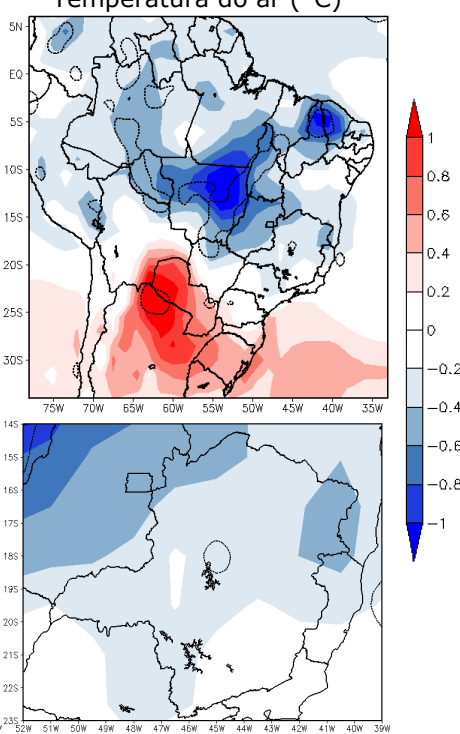

Figura 11 - Similar à Figura 5, mas durante os eventos frios do TNA.

\subsection{EVENTOS QUENTES DO TNA}

Um padrão relativamente oposto aos eventos frios do TNA é observado em eventos quentes. Anomalias positivas de TSM são observadas em todas as estações do ano no Atlântico Norte tropical e equatorial, inclusive na costa norte do Brasil (Figuras 12a-d). Entre o inverno e a primavera as anomalias quentes 
abrangem também a costa leste da região Nordeste, indo em direção à costa da região Sul do país na primavera e outono. Anomalias positivas de TSM também são observadas no Atlântico Sul extratropical. Com o aquecimento anômalo da TSM no Atlântico Norte, há supressão de convecção anômala no Atlântico Sul tropical em todas as estações do ano (Figuras $12 \mathrm{e}-\mathrm{h}$ ), sendo mais intensa no inverno.

Na primavera há supressão de convecção anômala do centro-norte de MG em direção ao norte, abrangendo toda a região Nordeste, parte da região Norte e nordeste do Mato Grosso (Figura 12e). Desta forma, há anomalias negativas de precipitação com orientação noroeste-sudeste entre o Amazonas até o extremo noroeste de MG (Figura 13a superior), com desvios de até -100 $\mathrm{mm}$ no Amazonas. Em MG déficit de precipitação ocorre no norte da mesorregião do Noroeste de Minas, bem como na Zona da Mata, com desvios de até $-50 \mathrm{~mm}$ (Figura 13a inferior). Por outro lado, no centro-sul do Brasil, abrangendo os estados de Mato Grosso do Sul, São Paulo e região Sul, há anomalias positivas de até $+75 \mathrm{~mm}$.

No verão as anomalias de supressão de convecção ocorrem na Bahia, nordeste de Goiás, leste de Tocantins e sul do Piauí/Maranhão (Figura 12f). As anomalias negativas de precipitação apresentam uma distribuição espacial com orientação noroeste-sudeste entre o Amazonas e o norte de MG (Figura 13b superior), com desvios de até $-100 \mathrm{~mm}$ no noroeste do Amazonas. Em MG as anomalias negativas de precipitação ocorrem nas mesorregiões Metropolitana de Belo Horizonte, Central Mineira, Noroeste de Minas, Norte de Minas, Jequitinhonha e Vale do Mucuri (Figura 13b inferior).

No outono a supressão de convecção anômala sobre o Brasil é observada na região Nordeste, com exceção da Bahia, bem como no extremo oeste do país (Figura 12g). Assim, anomalias negativas de precipitação ocorrem nas regiões Nordeste e Norte, além do Mato Grosso, com desvios de até -200 mm (Figura 13 c superior). Por outro lado, anomalias positivas de precipitação ocorrem na região Sul do Brasil. Não há anomalias de precipitação em MG com significância estatística (Figura 13c inferior).

No inverno há anomalias de supressão de convecção em grande parte do Brasil entre as latitudes em torno de $2^{\circ} \mathrm{S}$ e $23^{\circ} \mathrm{S}$ (Figura $12 \mathrm{~h}$ ). Portanto, déficit de precipitação ocorre com orientação noroeste sudeste entre o Amazonas e a Bahia/MG (Figura 13d superior), com anomalias de até $-100 \mathrm{~mm}$ no Amazonas. Em MG as anomalias negativas de até $-25 \mathrm{~mm}$ ocorrem nas mesorregiões Metropolitana de Belo Horizonte, Central Mineira, Noroeste de Minas, Norte de Minas e Jequitinhonha (Figura 13d inferior). Anomalias positivas de precipitação ocorrem no extremo norte do Maranhão e centro-leste do Rio Grande do Norte e Paraíba.

Domina anomalias positivas de temperatura do ar sobre o Brasil durante eventos quentes de TNA (Figuras 14a-d superiores): ao norte da região Sul na primavera; ao norte de cerca de $20^{\circ} \mathrm{S}$ no verão (com exceção do leste da região Nordeste e norte da região Norte); no norte da região Centro-Oeste, oeste da região Nordeste e Norte do Brasil no outono; e todo o país no inverno, com exceção do centro-sul do Rio Grande do Sul e parte da região Nordeste. Em MG as anomalias de temperatura do ar seguem o padrão observado no Brasil (Figuras 14a, 14b, 14d inferiores), com exceção do outono (sem significância estatística, Figura 14c inferior). No inverno e primavera há aquecimento anômalo em praticamente todo o Estado, com desvios de até $+0,8^{\circ} \mathrm{C}$. No verão 
as anomalias são positivas no centro-norte de MG: Triângulo Mineiro e Alto

Paranaíba, Central Mineira, Vale do Rio Doce, Vale do Mucuri, Jequitinhonha, Norte de Minas e Noroeste de Minas.

PRIMAVERA

(a)

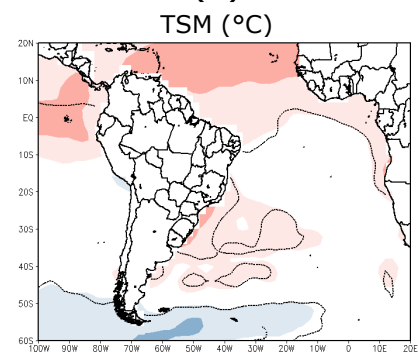

(e)

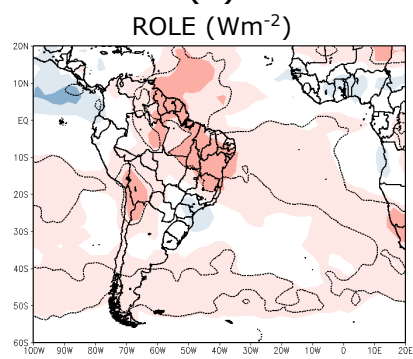

VERÃO

(b)

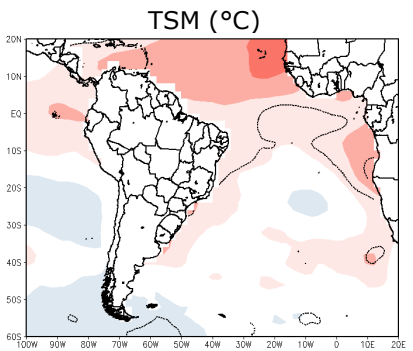

(f)

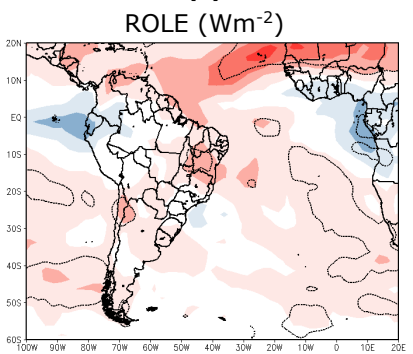

OUTONO

(C)

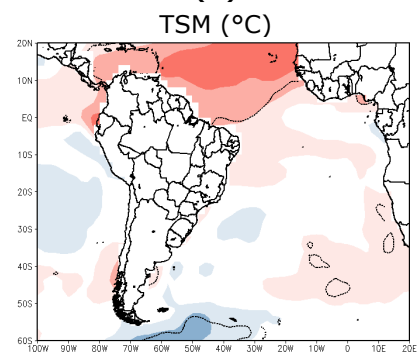

(g)

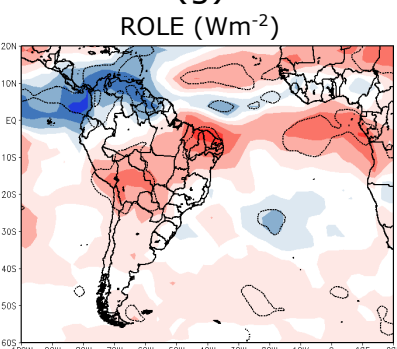

INVERNO

(d)

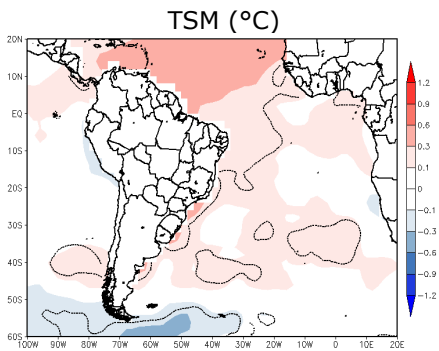

(h)

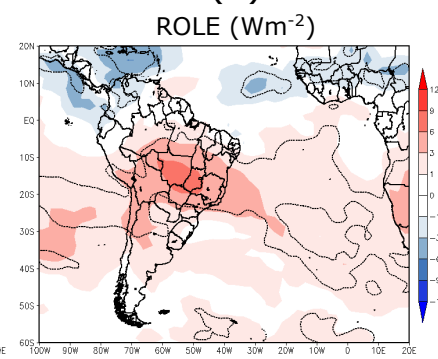

Figura 12 - Similar à Figura 3, mas durante os eventos quentes do TNA.

\section{PRIMAVERA}

(a)
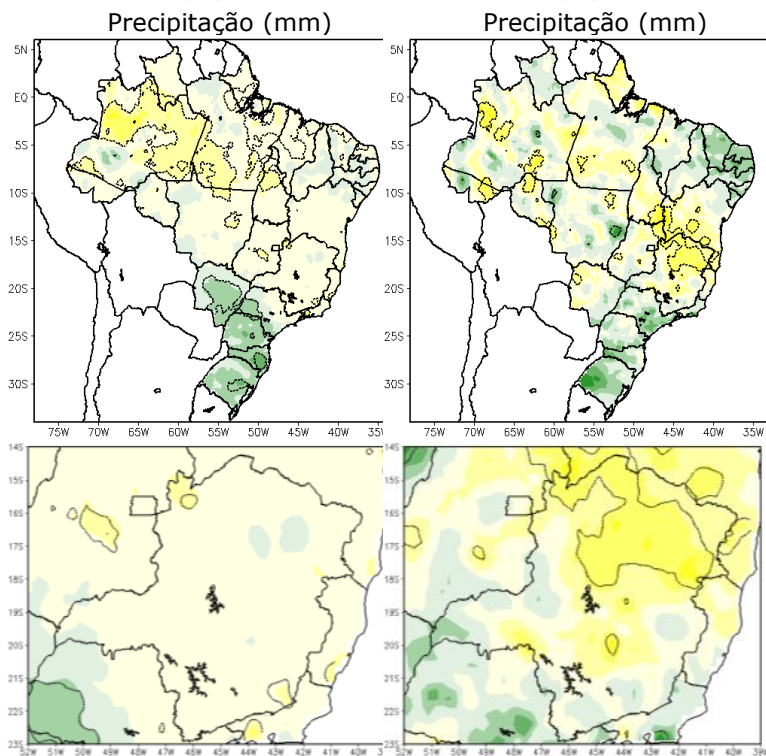

VERÃO

(b)
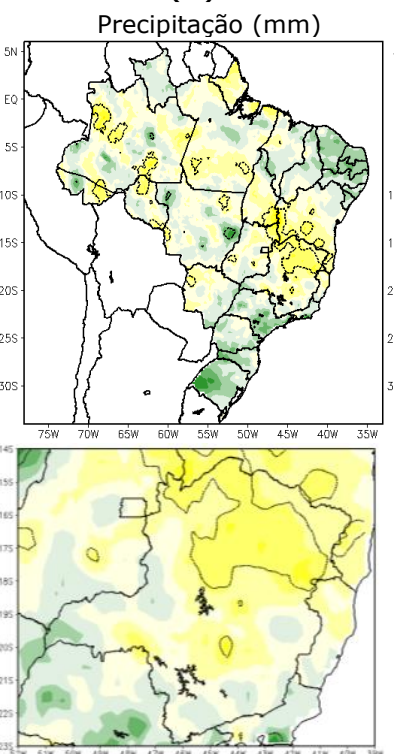

OUTONO

(c)
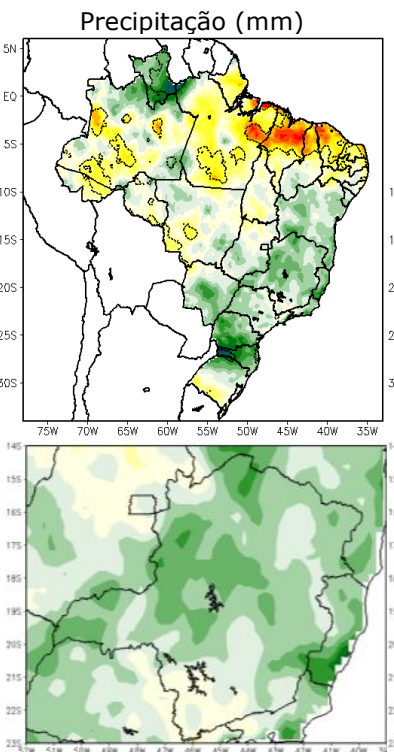

INVERNO

(d)

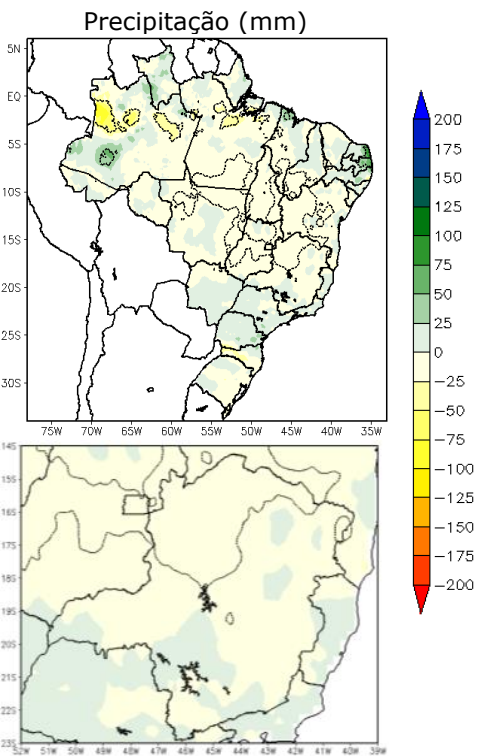

Figura 13 - Similar à Figura 4, mas durante os eventos quentes do TNA. 
PRIMAVERA

(a)

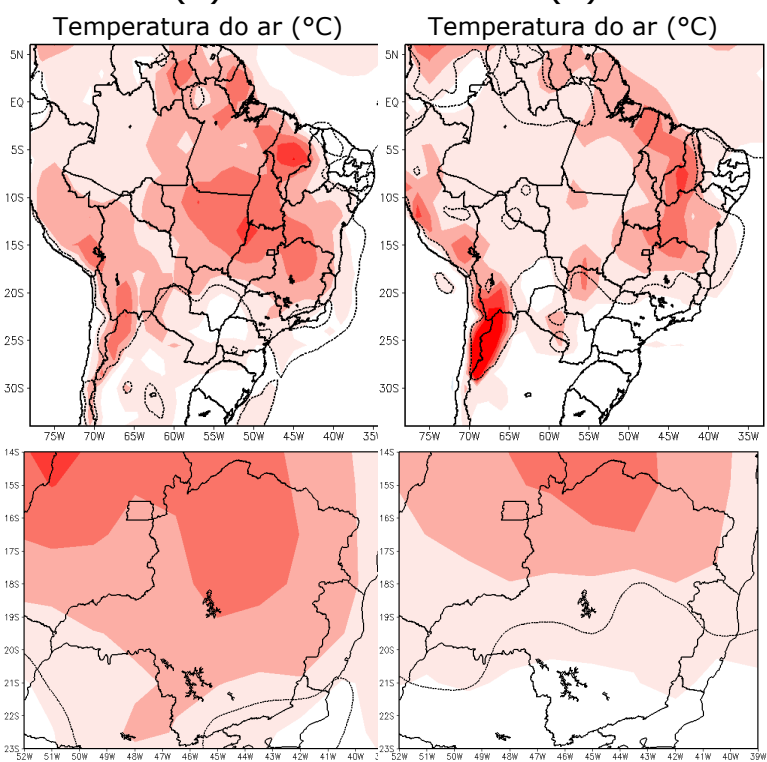

OUTONO

(c)
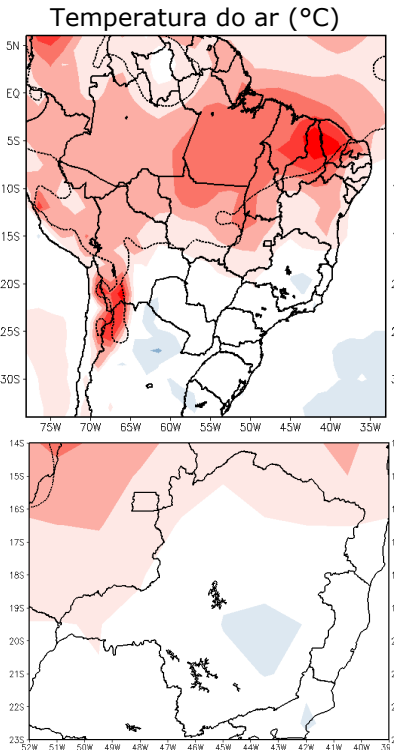

INVERNO

(d)

Temperatura do ar $\left({ }^{\circ} \mathrm{C}\right)$
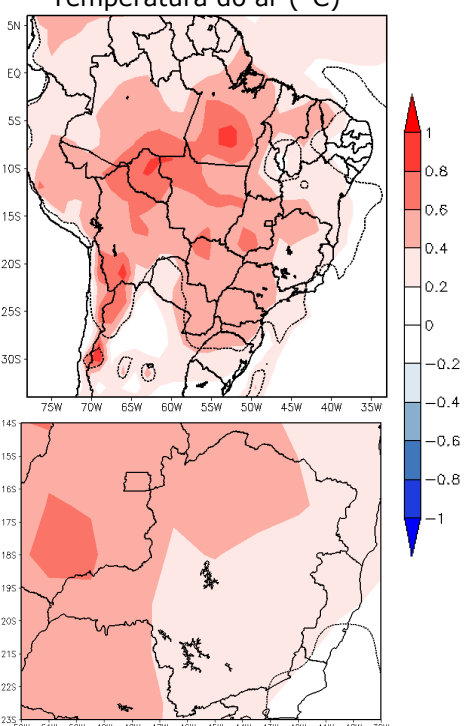

Figura 14 - Similar à Figura 5, mas durante os eventos quentes do TNA.

\section{CONCLUSÕES}

Neste estudo foi investigada a atividade convectiva associada às anomalias de TSM no Atlântico tropical através dos índices climáticos TSA e TNA, bem como os impactos climáticos sazonais no Brasil, com foco em MG. Foi observado que eventos frios (quentes) do TSA estão associados com anomalias negativas (positivas) de TSM no Atlântico tropical e anomalias positivas (negativas) no Atlântico Sul extratropical, semelhante à fase negativa (positiva) do Dipolo do Atlântico Sul (VENEGAS; MYSAK; STRAUB, 1997; HAARSMA, 2003; STERL; HAZELEGER, 2003; BOMBARDI et al., 2014). Um padrão espacial de tripolo de anomalias negativas/positivas/negativas (positivas/negativas/positivas) de ROLE entre o Atlântico Norte tropical, equador e Atlântico Sul tropical reflete o deslocamento para norte (para sul) da ZCIT do Atlântico. O padrão espacial das anomalias de precipitação sobre o Brasil durante eventos frios do TSA entre a primavera e outono é semelhante ao padrão de gangorra associado à ZCAS, indicando uma maior atividade convectiva. Desta forma, sobre o estado de MG há anomalias positivas de precipitação e negativas de temperatura do ar. A associação com eventos de ZCAS não é evidente em episódios quentes do TSA. Assim, em MG as anomalias de precipitação (outono e inverno) e de temperatura do ar (primavera, verão e outono) são opostas às observadas em eventos frios do TSA, ou seja, anomalias negativas de precipitação e positivas de temperatura do ar.

Por outro lado, em eventos frios (quentes) do TNA as anomalias negativas (positivas) de TSM ficam confinadas no Atlântico Norte tropical e equatorial. Entre a primavera e outono (inverno e verão) há anomalias positivas de TSM no centro-leste (oeste e leste) do Atlântico Sul tropical. No Atlântico Sul equatorial e tropical há convecção (supressão de convecção) anômala, o que demonstra o deslocamento da ZCIT do Atlântico para sul (para norte) de sua 
posição climatológica. Assim, em MG há anomalias positivas (negativas) de precipitação e anomalias negativas (positivas) de temperatura do ar na primavera (inverno, primavera e verão). A configuração espacial das anomalias de precipitação na primavera e verão associada aos eventos quentes do TNA é similar ao padrão de gangorra relacionado à ZCAS, porém deslocado para nordeste de sua posição média sobre o Brasil, entre o noroeste do Amazonas e os estados de MG/Espírito Santos.

Este estudo evidencia a importância de monitorar as anomalias de TSM no Atlântico tropical para melhor compreender e prever as variações de precipitação e temperatura do ar no estado de MG. A previsão da precipitação com pelo menos alguns meses de antecedência é importante para que se possam traçar estratégias que previnam situações de risco à sociedade e minimizem os custos socioeconômicos de mitigação e adaptação em relação aos impactos decorrentes dos eventuais eventos extremos hidrológicos. Além disso, possibilita a elaboração de políticas públicas mais eficientes, que servirão de instrumento para a tomada de decisões, com vistas à garantia de oferta de água para o abastecimento público, bem como para a geração de energia hidráulica e para a agricultura.

\section{REFERÊNCIAS BIBLIOGRÁFICAS}

ANA - AGÊNCIA NACIONAL DE ÁGUAS (Brasil). Atlas Brasil: abastecimento urbano de água. Brasília: ANA, 2010. Disponível em: http://atlas.ana.gov.br/Atlas/forms/Home.aspx.

ANA - AGÊNCIA NACIONAL DE ÁGUAS (Brasil). Conjuntura dos recursos hídricos no Brasil 2017: Relatório pleno / Agência Nacional de Águas. Brasília: ANA, 169 p., 2017.

BARROS, V. R.; GONZALEZ, M.; LIEBMANN, B.; CAMILLONI, I. Influence of the South Atlantic convergence zone and South Atlantic sea surface temperature on interannual Summer rainfall variability in Southeastern South America. Theor Appl Climatology, v. 67, p. 123-133, 2000.

BENGTSSON, L.; ARKIN, P.; BERRISFORD, P.; BOUGEAULT, P.; FOLLAND, C. K.; GORDON, C.; HAINES, K.; HODGES, K. I.; JONES, P.; KALLBERG, P.; RAYNER, N.; SIMMONS, A. J.; STAMMER, D.; THORNE, P. W.; UPPALA, S.; VOSE, R. S. The need for a dynamical climate reanalysis. Bull Am Meteorol Soc, v. 88, p. 495-501, 2007.

BERRISFORD, P.; DEE, D. P.; POLI, P.; BRUGGE, R.; FIELDING, M.; FUENTES, M.; KÅLlBERG, P. W.; KOBAYASHI, S.; UPPALA, S.; SIMMONS, A. 'The ERAInterim Archive'. ERA Report Series, n. 1. ECMWF: Reading, UK. 2009.

BOMBARDI, R. J.; CARVALHO, L. M. V., JONES, C.; REBOITA, M. S. Precipitation over eastern South America and the South Atlantic Sea surface temperature during neutral ENSO periods. Clim Dynam, v. 42, p. 1553-1568, 2014.

CARVALHO, L. M. V.; JONES, C.; LIEBMAN, B. The South Atlantic convergence zone: Intensity, form, persistence, relationships with intraseasonal to interannual activity and extreme rainfall. J Climate, v. 17, p. 88-108, 2004.

CASARIN, D. P.; KOUSKY, V. E. Anomalias de precipitação no sul do Brasil e variações na circulação atmosférica. Rev Bras Meteor, v. 1, p. 83-90, 1986. 
CHAVES, R. R.; NOBRE, P. Interactions between sea surface temperature over the South Atlantic Ocean and the South Atlantic Convergence Zone. Geophys Res Lett, v. 31, L03204, 2004.

CHIANG, J. C. H.; KUSHNIR, Y.; GIANNINI, A. Deconstructing Atlantic Intertropical Convergence Zone variability: Influence of the local crossequatorial sea surface temperature gradient and remote forcing from the eastern equatorial Pacific. J Geophys Res, v. 107, n. D1, 4004, 2002.

CHRISTOPHERSON, W. R. Geossistemas: Uma Introdução À Geografia Física. 7 ed., Porto Alegre: Bookman. 728 p., 2012.

DEE, D. P. Bias and data assimilation. Q J R Meteorol Soc, v. 131, p. 3323-3343, 2005.

ENFIELD, D. B.; MESTAS, A. M.; MAYER, D. A.; CID-SERRANO, L. How ubiquitous is the dipole relationship in tropical Atlantic sea surface temperatures? J Geophys Res, v. 104, p. 7841 7848, 1999.

GAN, M. A.; KOUSKY, V. E.; ROPELEWSKI, C. F. The South America monsoon circulation and its relationship to rainfall over West-Central Brazil. J Climate, v. 17, p. 47-66, 2004.

GIANNINI, A.; KUSHNIR, Y.; CANE, M. A. Interannual Variability of Caribbean Rainfall, ENSO, and the Atlantic Ocean. J Climate, v. 13, p. 297-311, jan. 2000.

GRIMM, A. M. The El Niño impact on the summer monsoon in Brazil: regional processes versus remote influences. J Climate, v. 16, p. 263-280, 2003.

HAARSMA, R. J. Atmospheric response to South Atlantic SST dipole. Geophys Res Lett, v. 30, n. 16, 2003.

IBGE - Instituto Brasileiro de Geografia e Estatística (Brasil). Censo Demográfico 2010. Brasília: IBGE, 2010. Disponível em: http://censo2010.ibge.gov.br.

IBGE - INSTITUTO BRASILEIRO DE GEOGRAFIA E ESTATÍSTICA (Brasil). Brasil em Síntese: Panorama de Minas Gerais, 2018. Disponível em: <https://cidades.ibge.gov.br/brasil/mg/ panorama>. Acesso em 22 jun. 2018.

KAYANO, M. T.; OLIVEIRA, C. P.; ANDREOLI, R. V. Interannual relations between South American rainfall and tropical sea surface temperature anomalies before and after 1976. Int J Climatol, v. 29, p. 1439-1448, 2009.

KOUSKY, V. E.; ROPELEWSKI, C. F. The tropospheric seasonally varying mean climate over the Western Hemisphere (1975-1995). NCEP/Climate Prediction Center Atlas, n. 3, 135 p., 1997.

LIEBMANN, B.; KILADIS, G. N.; MARENGO, J. A.; AMBRIZZI, T.; GLICK, J. D. Submonthly convective variability over South America and the South Atlantic convergence zone. J Climate, v. 12, p. 1877-1891, 1999.

LIEBMANN, B.; SMITH, C. A. Description of a Complete (Interpolated) Outgoing Longwave Radiation Dataset. B Am Meteorol Soc, v. 77, p. 1275-1277, 1996.

MARENGO, J. A.; SOARES, W. R.; SAULO, C.; NICOLINI, M. Climatology of the Low-Level Jet East of the Andes as derived from the NCEP-NCAR Reanalyses: Characteristics and Temporal Variability. J Climate, v. 17, p. 2261-2280, 2004 
MOURA, A. D.; SHUKLA, J. On the dynamics of droughts in Northeast Brazil: observation, theory, and numerical experiments with a general circulation model. J Atmos Sci, v. 38, p. 2653-1675, dez. 1981.

MUZA, M. N.; CARVALHO, L. M. V.; JONES, C.; LIEBMANN, B. Intraseasonal and Interannual Variability of Extreme Dry and Wet Events over Southeastern South America and the Subtropical Atlantic during Austral Summer. J Climate, v. 22, p. 1682-1699, 2009.

NATIONAL CENTER FOR ATMOSPHERIC RESEARCH STAFF (Eds). Last modified 03 Jun 2016. "The Climate Data Guide: Merged Hadley-NOAA/OI Sea Surface Temperature \& Sea-Ice Concentration (Hurrell et al, 2008)." Retrieved from https://climatedataguide.ucar.edu/ climate-data/merged-hadley-noaaoi-seasurface-temperature-sea-ice-concentration-hurrell-et-al-2008.

NOBRE, P.; SHUKLA, J. Variations of sea surface temperature, wind stress, and rainfall over the tropical Atlantic and South America. J Climate, v. 9, p. 24642479, 1996.

NOGUÉS-PAEGLE, J.; MO, K. C. Alternating wet and dry conditions over South America during summer. Mon Wea Rev, v. 125, p. 279-291, 1997.

PAMPUCH, L. A.; DRUMOND, A.; GIMENO, L.; AMBRIZZI, T. Anomalous patterns of SST and moisture sources in the South Atlantic Ocean associated with dry events in southeastern Brazil. Int J Climatol, v. 36, p. 4913-4928, 2016.

RAO, V. B.; CAVALCANTI, I. F. A.; HADA, K. Annual variation of rainfall over Brazil and water vapor characteristics over South America. J Geophys Res, v. 101, p. 539-551, 1996.

REBOITA, M. S.; RODRIgUeS, M.; SILVA, L. F.; ALVES, M. A. Aspectos climáticos do estado de Minas Gerais. Brasileira de Climatologia, v. 17, p. 206226, jul/dez 2015.

RODRIGUES, R. R.; HAARSMA, R. J.; CAMPOS, E. J. D.; AMBRIZZI, T. The impacts of inter-El Nino variability on the Tropical Atlantic and Northeast Brazil climate. J Climate, v. 24, p. 3402-3422, 2011.

SILVA, E. D.; REBOITA, M. S. Estudo da precipitação no estado de Minas GeraisMG. Revista Brasileira de Climatologia, v. 13, p. 120-136, jul/dez 2013.

SILVA, V. B. S.; KOUSKY, V. E. The South American Monsoon System: Climatology and Variability, Modern Climatology, Dr Shih-Yu Wang (Ed.), InTech, 2012.

SMITH, T. M.; REYNOLDS, R. W.; PETERSON, T. C.; LAWRIMORE, J. Improvements to NOAA's Historical Merged Land-Ocean Surface Temperature Analysis (1880-2006). J Climate, v. 21, p. 2283-2296, 2008.

STERL A.; HAZELEGER, W. Coupled variability and air-sea interaction in the South Atlantic Ocean. Clim Dynam, v. 21, p. 559-571, 2003.

UPPALA, S.; DEE, D.; KOBAYASHI, S.; BERRISFORD, P.; SIMMONS, A. Towards a climate data assimilation system: status update of ERA-interim. ECMWF Newsletter, v. 115, p. 12-18, 2008.

UVO, C. B.; REPELLI, C. A.; ZEBIAK, S. E.; KUSHNIR, Y. The Relationships between Tropical Pacific and Atlantic SST and Northeast Brazil Monthly Precipitation. J Climate, v. 11, 1998. 
VENEGAS, S. A.; MYSAK, L. A.; STRAUB, D. N. Atmosphere-ocean coupled variability in the South Atlantic. J Climate, v. 10, p. 2904-2920, 1997.

VERA, C; HIGGINS, W.; AMADOR, J.; AMBRIZZI, T.; GARREAUD, R.; GOCHIS, D.; GUTZLER, D.; LETTENMAIER, D.; MARENGO, J.; MECHOSO, C. R.; NOGUESPAEGLE, J.; SILVA DIAS, P. L.; ZHANG, C. Towards a unified view of the American Monsoon systems. J Climate, v. 19, p. 4977-5000, 2006.

XAVIER, A. C.; KING, C. W.; SCANLON, B. R. An update of Xavier, King and Scanlon (2016) daily precipitation gridded data set for the Brazil. Proceedings of the 18th Brazilian Symposium on Remote Sensing, Santos, SP, Brazil. p. 28-31, 2017.

XAVIER, A. C.; KING, C. W.; SCANLON, B. R. Daily gridded meteorological variables in Brazil (1980-2013). Int J Climatol, v. 36, p. 2644-2659, 2016.

ZHOU, J.; LAU, K. M. Does a Monsoon Climate Exist over South America? J Climate, v. 11, p. 1020-1040, 1998 